\title{
The Reality of the Promised Increase in Customer Protection Under the Insurance Distribution Directive
}

\section{Insurers' Pre-contractual Obligations Under Article 20 of the IDD: IPIDs}

\author{
Christian Bo Kolding-Krøger, Regitze Aalykke Hansen, and Amelie Brofeldt
}

\section{Introduction}

\subsection{Hypothesis and Methodology}

The Insurance Mediation Directive ("IMD") was revised and replaced by the Insurance Distribution Directive ${ }^{2}$ ("IDD") in 2018. One of the objectives of the revision was to increase the protection of policyholders ('customers') by, inter alia, focusing on customer protection. ${ }^{3}$ In order to meet that objective, Article 20 provides rules on the conduct of business that insurance distributers ('insurers') must comply with before entering into an insurance contract with a customer when advice is not given to such customer, including the obligation for an insurer to enable a customer to make an informed decision.

This chapter explores whether Article 20 of the IDD actually makes it easier for customers to compare various insurance products in the pre-contractual phase, and whether, in reality, insurers are able to meet the objectives set out in the IDD based on the rules set out in the IDD and the Implementing Regulation.

\footnotetext{
${ }^{1}$ Directive 2002/92/EC of the European Parliament and of the Council of 9 December 2002 on insurance mediation. The Directive was implemented into Danish law by the previous Danish Insurance Mediation Act (Consolidated Act no 1065 of 22 August 2013 on Insurance Mediation as amended).

${ }^{2}$ Directive (EU) 2016/97 of the European Parliament and of the Council of 20 January 2016 on insurance distribution (recast).

${ }^{3}$ Proposal for a Directive of the European Parliament and of the Council on Insurance Mediation (recast), COM/2012/0360 final - 2012/0175 (COD), section 1.1.
}

C. B. Kolding-Krøger $(\bowtie) \cdot$ R. A. Hansen $\cdot$ A. Brofeldt

Poul Schmith, Copenhagen, Denmark

e-mail: cbk@poulschmith.com; reha@poulschmith.com; ambr@poulschmith.com

P. Marano, K. Noussia (eds.), Insurance Distribution Directive, AIDA Europe

Research Series on Insurance Law and Regulation 3,

https://doi.org/10.1007/978-3-030-52738-9_16 
The authors' hypothesis is that the promised increase in customer protection by introducing Insurance Product Information Documents ("IPID") under the IDD, has not actually materialised. Rather, it has the potential to leave both customers and insurers confused.

Methodologically, this chapter will analyse different IPIDs: two relating to compulsory insurance products (Workers' Compensation Insurance and ThirdParty Motor Liability Insurance) and one relating to a non-compulsory insurance product (Contents Insurance).

The analysis will cover IPIDs and underlying insurance terms for insurance products promulgated by at least five different insurers. The geographical scope of the chapter is restricted to Denmark. However, on the assumption that the IDD has been implemented by insurers on the Danish market in the same way as those on the wider European market, the analysis and conclusions reached are applicable across other European jurisdictions.

As the analysis is dependent on there being both an IPID and underlying insurance terms publicly available for each of the insurance products, the analysis will include five insurers who (1) distributes the analysed insurance product, and (2) has both the IPID and underlying insurance terms for this product available online. Consequently, the analysis will not include IPIDs from the same five insurers for each of the three insurance products. In total eight insurers are included.

It is the authors opinion that the eight chosen insurers represent a relevant picture of the Danish insurance market which is dominated by larger players and with smaller-often regional-alternatives. Even though all but one of the included insurers are among the 20 largest insurers in Denmark when looking at gross premium they cannot all be considered big companies. Thus, the eight insurers in the analysis includes one large Danish insurer that also does business in other Scandinavian countries; one large Danish insurer that is a part of a worldwide insurance group; and one large Scandinavian insurer with physical presence in Denmark and a large market share in both its home country and Denmark. Also, it includes two large Danish insurers that to the authors' knowledge only does business in Denmark and three mid-sized to small Danish insurers that also only does business in Denmark.

The authors did not make any findings related to the size or market share of the insurers, nor was the IPIDs from the foreign insurer or from the insurer that is a member of a worldwide group notably different from the IPIDs of the other included insurers.

All the insurers whose IPIDs and underlying terms of cover have been examined are hereinafter referred to, respectively, as A-H.

Although more insurance companies, jurisdictions and insurance products might have been included in a greater examination, the results of the in-depth examination of the chosen IPIDs, coupled with a high-level examination of other products from other insurers, demonstrates a consistent overall trend amongst all IPIDs. The authors are confident that their in-depth examination of the chosen IPIDs is reflective of the wider market and that the analysis and conclusions reached are applicable across other European jurisdictions. 
The authors' analysis has also revealed that IPIDs and insurance terms-especially for commercial insurance products - are not always publicly available, or indeed available at all other than by virtue of a customer directly approaching an insurer to enquire about purchasing cover. As underlying insurance terms are necessary in order to analyse whether IPIDs actually give a fair presentation of the insurance cover, which presentation can facilitate customer comparisons of different insurance products, the authors have chosen only to include products where both the IPIDs and underlying insurance terms were publicly available.

The authors also wish to note a wider issue regarding the effectiveness of IPIDs providing customers with an effective means for comparing insurance products in the pre-contractual phase. The simple point is that, to a large extent, IPIDs are not made available to a customer prior to such customer actually concluding a written or oral contract with an insurer.

The analysis of each insurance product will, as a starting point, follow the structure of the IPID by utilising the relevant individual headings, cf. the Implementing Regulation, Article 6(1)(a)-(j). In the interests of brevity and in order to facilitate comprehension, the examination will not include a complete reproduction of the relevant IPIDs. Instead, it will focus on two points: Those where insurers have adopted a completely uniform approach in their IPIDs; and those where there are discrepancies between the insurers' completion of the different sections under the headlines. Accordingly, it is the points where there is either significant uniformity or discrepancy between IPIDs which provide the best launch-pad from which to discuss whether IPIDs actually contribute to give the customer a useful basis for comparing insurance products.

Having analysed the selected IPIDs, the authors examine the challenges that tend to be presented by the same and explore how such challenges may be resolved.

\subsection{Structure}

Section 1 sets out a short introduction to the problem analysed in this chapter and the hypothesis, methodology, and structure adopted in carrying out such analysis.

Section 2 sets out the legal landscape for the distribution of insurance for policyholders in the EU after the introduction of the IDD.

Section 3 sets out to prove the hypothesis that the introduction of IPIDs, which was designed to give customers a basis for making informed decisions, has not, in fact, resulted in increased customer protection. The hypothesis will be tested by an examination of selected IPIDs for Third Party Motor Liability Insurance (compulsory in Denmark), Workers' Compensation Insurance (compulsory in Denmark), and Contents Insurance (not compulsory in Denmark).

Finally, Sect. 4 sets out the authors' conclusion regarding whether the rules regarding IPIDs mandated in IDD have, in fact, resulted in increased customer protection. In particular, such conclusion will address the issue of whether, in reality, 
insurers are able to meet the objective of increasing customer protection based on the assumptions set by the IDD and the Implementing Regulation.

\section{Introduction to Customer Protection Under the IDD}

Before the commencement of the IDD, the sale of insurance products was regulated by the IMD. As the IMD only concerned insurance agents and brokers, it did not contain rules on the sale of insurance products directly from the insurers to customers, cf. Article 1 of the IMD.

The IMD was revised and replaced by the IDD, which entered into force on 22 February 2016. Originally, the IDD should have been implemented by Member States on 23 February 2018, but the implementation date was, ultimately, delayed until 1 July 2018, with the date of application being 1 October 2018, from which date the IMD was repealed. ${ }^{4}$

It appears, from the proposal for the IDD, that the objective of the revision to the IMD was designed to ensure consistency of terms between all participants involved in the sale of insurance products and to increase customer protection. In the proposal, the general objectives were described as being ensuring a level playing field, protection of customers and market integration. ${ }^{5}$

From the wording of recital 6 it is apparent that, as regards customer protection, the objective of the IDD is to ensure the same level of protection for customer irrespective of a particular customer's identity and irrespective of how such a customer purchases an insurance product (in this regard see also Recital 8). ${ }^{6}$

The rules on conduct of business can be found in Chapter V of the IDD. The general principle underpinning such rules is found in Article 17(1), which provides that insurance distributors must always act honestly, fairly and professionally in accordance with the best interests of their customers. ${ }^{7}$

In order to satisfy this principle, the following articles lay down insurance distributors' obligations prior to concluding any contracts with customers.

\footnotetext{
${ }^{4}$ See Article 1 of Directive (EU) 2018/411 of the European Parliament and of the Council of 14 March 2018 amending Directive (EU) 2016/97 as regards the date of application of the Member States' transposition measures.

${ }^{5}$ Proposal for a Directive of the European Parliament and of the Council on Insurance Mediation (recast), COM/2012/0360 final - 2012/0175 (COD), section 1.1.

${ }^{6}(6)$ Consumers should benefit from the same level of protection despite the differences between distribution channels. In order to guarantee that the same level of protection applies and that the consumer can benefit from comparable standards, in particular in the area of the disclosure of information, a level playing field between distributors is essential. (Recital 6 of the IDD).

${ }^{7} 1$. Member States shall ensure that, when carrying out insurance distribution, insurance distributors always act honestly, fairly and professionally in accordance with the best interests of their customers. (Article 17(1) of the IDD).
} 
Articles 18 and 19 contain the general information that insurers and insurance intermediaries must give their customers before concluding an insurance contract. Article 20(1) then stipulates that:

Prior to the conclusion of an insurance contract, the insurance distributor shall specify, on the basis of information obtained from the customer, the demands and the needs of that customer and shall provide the customer with objective information about the insurance product in a comprehensible form to allow that customer to make an informed decision.

Any contract proposed shall be consistent with the customer's insurance demands and needs.

Thus, insurance distributors are required to enable the customer to make an informed decision by giving objective and comprehensible information about the insurance product before they can be considered to have met the objective of Article $17(1)$ and therefore can be said to have acted in accordance with the customer's best interest. ${ }^{8}$

In the following section, the authors analyse whether the rules on IPIDs actually result in increased customer protection, and whether insurers are, in fact, able to comply with these rules in practice.

\section{Insurance Product Information Documents (IPIDs)}

\subsection{The Rules on IPIDs}

Article 20(4) of the IDD provides that prior to the conclusion of a contract, the insurance distributor in question must provide the relevant information about the insurance product it is selling in a form comprehensible to a customer in order to allow the customer to make an informed decision, whilst also taking into account the

\footnotetext{
${ }^{8}$ The benefits for insurance customers and society at large afforded by introducing such advice standards, are set out in the Commission Staff Working Document (Commission Staff Working Document Executive Summary of the Impact Assessment accompanying the document Proposal for a Directive of the European Parliament and of the Council on Insurance Mediation, SWD/2012/ 0192 final, section 7.1.):
}

By introducing improved and harmonised advice standards, consumers will gain benefits through an improved comparability of offers, including across different distribution channels. This is likely to lead to an improved understanding by consumers of the services and products on offer. As a result, consumers will be inclined to compare offers and shop around for products and deals better suited to their needs. This reduces the cost/price paid by the consumer.

The consumer needs to buy insurance policies which fit his needs and financial situation. Otherwise, there is a high risk of an early withdrawal on the unsuitable policy and consumer dissatisfaction.

[...] The benefits to consumers and society as a whole from the introduction of high and harmonised advice standards come through a reduction in early withdrawals (reduction in defaults). 
complexity of the insurance product and the particular type of customer. Further, Article 20(5), that the information referred to in paragraph 4 have to be provided by way of a standardised insurance product information document. ${ }^{9}$

Article 20(7) states that the product information document must meet certain formal requirements, including that the words 'standardised insurance product information document' (IPID) must appear on the face of the document. Further, Article 20(8) specifies the information that the document must contain. The product information documents, or IPIDs, must be drawn up by the manufacturer of the non-life insurance product, cf. Article 20(6). In short, the point is that all customers must be provided with an IPID produced by the manufacturer, irrespective of who is actually distributing the particular insurance product.

The rules on IPIDs are a new feature of the IDD regime as compared to that under the IMD. Indeed, the rules were not actually included in the first proposal for the IDD and such early draft provided only that the information in question could be given in standardised format. ${ }^{10}$ It was only in a proposed amendment that the current Article 20(5) was introduced. ${ }^{11}$

Only in the supplementary report by the Committee on Economic and Monetary Affairs did the document get its full name and the European Insurance and Occupational Pensions Authority ("EIOPA") was authorised to draft implementing technical standards regarding a standardised presentation format. ${ }^{12}$

The objective of an IPID and the standard by which its effectiveness must be judged is to make the customer able to make an informed decision about insurance products by giving comparable standardised information. ${ }^{13}$

\footnotetext{
${ }^{9}$ In relation to the distribution of non-life insurance products as listed in Annex I to Directive 2009/ 138/EC, the information referred to in paragraph 4 of this Article shall be provided by way of a standardised insurance product information document on paper or on another durable medium. (Article 20(5) of the IDD).

${ }^{10}$ Proposal for a Directive of the European Parliament and of the Council on Insurance Mediation (recast), COM/2012/0360 final - 2012/0175 (COD), Article 25(4). The proposal was given as recital 4a and Article 18(4) in the Opinion of the Internal Market and Consumer Protection.

${ }^{11}$ In the amended proposal, the following was written in Article 18(4) about the duty of information:

[...] It shall be provided in a standardised information sheet by way of a product information document (PID) in plain language [... ] (see Opinion of the Internal Market and Consumer Protection (30.4.2013) on the proposal for a directive of the European Parliament and of the Council on insurance mediation (recast) $(\mathrm{COM}(2012) 0360$ - C7-0180/2012 - 2012/0175 (COD)), A7-0085/2014.).
}

${ }^{12}$ Supplementary Report of the Committee on Economic and Monetary Affairs on the proposal for a directive of the European Parliament and of the Council on insurance mediation (recast) (COM (2012)0360 - C7-0180/2012 - 2012/0175(COD)), A8-0315/2015.

${ }^{13}$ See Recital 48 of the IDD which describes the objective of the IPID as follows:

Prior to the conclusion of a contract, including in the case of non-advised sales, the customer should be given the relevant information about the insurance product to allow the customer to make an informed decision. An insurance product information document should provide standardised information about non-life insurance products. 


\subsection{EIOPA's Work on the Standardised Presentation Format}

EIOPA was given the task of drafting implementing technical standards regarding the standardised presentation format of the IPID which was manded by Article 20 (9) of the IDD.

As part of the development of this draft, EIOPA carried out consumer testing and consulted national authorities. The result of this work was the adoption of the Implementing Regulation for the IDD that contains the rules on the standardised presentation format for IPIDs. ${ }^{14}$

EIOPA's draft provides that the IPIDs'

[...] objective is to ensure that the customer has the relevant information about a non-life insurance product to allow him to easily compare between different product offers and to make an informed decision about whether or not to purchase the product. ${ }^{15}$

This objective was reiterated in Recital 1 of the Implementing Regulation (as read with Recital 3).

The Implementing Regulation contains a detailed description of the requirements pertaining to the format of the IPID, including its length, headings and icons. The Annex to the Implementing Regulation contains a standardised format which meets the requirements.

However, the Regulation does not contain any rules on or guidelines for the substantive contents of the document. It appears from Recital 2 that Article 20(8) of the IDD stipulates the information that the document must contain. However, Article 20(8) only contains contents which (more or less) correspond to the headings in EIOPA's standardised format. Apart from this, no other rules on completion of the IPIDs have been laid down (whether in the Regulation or otherwise).

EIOPA's draft implementing technical standards provide that IPIDs are supplementary to the underlying insurance policy terms and conditions, and that any tailoring of a product to a particular customer must be achieved through modification of the underlying policy terms and conditions, and not through the IPID. ${ }^{16}$ Accordingly, it should, in theory, be possible to draft the IPIDs very generally and without including any add-ons or optional cover.

In this regard, see also Recital 16, which provides that:

This Directive should ensure that the same level of consumer protection applies and that all consumers can benefit from comparable standards. [...].

${ }^{14}$ Commission Implementing Regulation (EU) 2017/1469 of 11 August 2017 laying down a standardised presentation format for the insurance product information document.

${ }^{15}$ Draft Implementing Technical Standards concerning a standardised presentation format for the Insurance Product Information Document of the Insurance Distribution Directive of 7 February 2017, EIOPA-17/056, page 3, section 1.

${ }^{16}$ Draft Implementing Technical Standards concerning a standardised presentation format for the Insurance Product Information Document of the Insurance Distribution Directive of 7 February 2017, EIOPA-17/056, page 4, section 6. 
In response to EIOPA's consultation paper on the draft implementing technical standards, several trade organisations commented on the balance between, on the one hand enabling the customer to make an informed decision, and on the other giving insurance manufacturers the flexibility to include the relevant information on the specific insurance product. ${ }^{17}$

Moreover, doubts were raised in EIOPA's consultations about whether EIOPA's proposed presentation format would meet the objective of ensuring customers were able to make an informed decision. For example, Eurofinas said that it was important to use a template that is clear and straightforward for all parties involved, and that the headings used in the IPID-template left room for interpretation. ${ }^{18}$ Eurofinas thus requested guidelines about how the IPIDs were to be completed in practice.

\footnotetext{
${ }^{17}$ As an example, the Danish Insurance Association commented on the level of standardisation of the IPIDs (Comments received by Danish Insurance Association to EIOPA-CP-16-007: Consultation Paper on the proposal for the Implementing Technical Standards on a standardised presentation format of the Insurance Product Information Document (IPID) under the Insurance Distribution Directive (IDD), page 3):
}

EIOPA should ensure that the level of standardisation introduced in the final IPID leaves manufacturers the necessary flexibility to make an IPID as meaningful as possible for customers.

In order to achieve a successful IPID, flexibility must be introduced for the insurers to be able to ensure that the IPID provides relevant information for the consumer to make an informed decision, while also taken into account the complexity of the insurance products. Introducing a single standardised format should be balanced with the wide range of products that will be covered by the IPID.

As to the proposed length of the IPID, the Danish Insurance Association said (Comments received by Danish Insurance Association to EIOPA-CP-16-007: Consultation Paper on the proposal for the Implementing Technical Standards on a standardised presentation format of the Insurance Product Information Document (IPID) under the Insurance Distribution Directive (IDD), page 11):

We agree with EIOPA that the IPID should not be too elaborate and should not result in a de facto duplication of the policy terms and conditions, whilst being accurate and non-misleading.

As such, the objective was, at least from a Danish perspective (which perspective the authors believe was broadly shared across the European Union), to find a balance between providing the flexibility required to enable insurers to give the relevant information, whilst ensuring that the IPIDs did not become a duplicate of the full insurance policy terms and conditions.

${ }^{18}$ See the European Federation of Finance House Association (Eurofinas) in Comments received by Eurofinas to EIOPA-CP-16-007: Consultation Paper on the proposal for the Implementing Technical Standards on a standardised presentation format of the Insurance Product Information Document (IPID) under the Insurance Distribution Directive (IDD), page 3-4:

In order to fully enable consumers to make such well-informed decisions, it is important to use a template that is clear and straightforward for all parties involved, i.e. easy-to-complete for all non-life insurance manufacturers, easy-to-use by intermediaries within all channels and easy-to-understand for all customers. [...]

In addition, we think that the headings, as currently phrased, leave room for interpretation. For example, as an insurance manufacturer, how do you determine what main risks covered or not covered - you are required to list for your product. It would be helpful if the 
Assuralia expressed concerns regarding the specification of add-ons, optional covers etc. ${ }^{19}$ Assuralia's concerns were shared by several other respondents to EIOPA's consultation, including AMICE ${ }^{20}$ the Financial Services Consumer Panel (FSCP) ${ }^{21}$ and Test Achats. ${ }^{22}$

As such, it was proposed that, in the event a particular insurance product contained a number of different coverage levels, or if an insurance product offered different optional coverage, several different and independent IPIDs were to be drawn up in respect of such insurance product, each of which set out different permutations of coverage. In short, one IPID should only contain one type of cover.

EIOPA could provide indications on how exhaustive this information should be and what benchmarks should be used.

${ }^{19}$ See the Belgian Insurance Association (Assuralia) in Comments received by Assuralia to EIOPACP-16-007: Consultation Paper on the proposal for the Implementing Technical Standards on a standardised presentation format of the Insurance Product Information Document (IPID) under the Insurance Distribution Directive (IDD), page 2:

We regret that EIOPA's work focuses primarily on the comparability of products through extensive standardization of the IPID rather than providing customers with useful information. The proposed format pays little attention to the presentation of options and the distinction between basic (standard, not optional), and optional covers for example, while such information is key for a customer's understanding of the product and could influence his decision to purchase the product. We therefore call on EIOPA to leave manufacturers sufficient flexibility to explain the main product features they consider relevant for the customer in the IPID.

${ }^{20}$ Association of Mutual Insurers and Insurance Cooperatives in Europe (AMICE).

${ }^{21}$ See the Financial Services Consumer Panel (FSCP) in Comments received by FSCP to EIOPACP-16-007: Consultation Paper on the proposal for the Implementing Technical Standards on a standardised presentation format of the Insurance Product Information Document (IPID) under the Insurance Distribution Directive (IDD), page 2:

The panel believes a single IPID will not be sufficient to cover all aspects of insurance products in cases where such products have more than one type of policy. The panel recommends EIOPA to require additional IPID's be made available to consumers when offered add on policies. This can be the case with legal insurance attached to home insurance for example. A single IPID will not capture all the terms and conditions of such separate policies and be mis-leading to consumers. As such, any separate policy should be subject to a separate IPID.

${ }^{22}$ See the Belgian Consumer Organisation (Association Belge des Consommateurs ASBL, Test Achats) in Comments received by Test Achats to EIOPA-CP-16-007: Consultation Paper on the proposal for the Implementing Technical Standards on a standardised presentation format of the Insurance Product Information Document (IPID) under the Insurance Distribution Directive (IDD), page 2:

The main features of a cover, mentioned in an IPID, should stay identical regardless of the number of other covers with which it is combined. A single IPID already offers not much space to describe the main features of one cover. A single IPID on two pages of an A4 page becomes a misleading document if it has to summarize the key information of more than one cover of a multi-risk policy. 
The Dutch Association of Insurers criticised EIOPA's presentation format, because they thought it limiting existing initiatives providing more radical consumer protection. ${ }^{23}$ Consequently, the Association proposed how the IPIDs should be drawn up by referring to the already existing Dutch IPID, and hereby emphasised that they thought it necessary to define which were the main characteristics insurance manufacturers were supposed to describe for a specific insurance product. ${ }^{24}$ This was necessary, so the Dutch Association said, in order to make the IPIDs comparable.

Nonetheless, the points of criticism set out above, were not, ultimately, taken into account. Thus, different presentation formats for each insurance product were not developed (as suggested by The Dutch Association of Insurers) and no main characteristics was defined. It has not been made clear whether each IPID should only contain the main features of the product, or whether each IPID should include the various permutations possible with add-ons or optional coverage. The problem regarding add-ons and optional coverage (as mentioned by Test Achats and FSCP amongst others) has not been addressed. Nor was any guidance on the completion of the IPIDs provided (as requested by Eurofinas). However, EIOPA did take into consideration the insurance manufacturers desire for flexibility and autonomy.

The following paragraphs discuss whether the current IPID format actually meets the IDD's objective of enabling customers to make an informed decision based on comparable information on various insurance products, or whether the criticisms and concerns levelled by the consulted organisations are still relevant.

\footnotetext{
${ }^{23}$ See the Dutch Association of Insurers in Comments received by the Dutch Association of Insurers to EIOPA-CP-16-007: Consultation Paper on the proposal for the Implementing Technical Standards on a standardised presentation format of the Insurance Product Information Document (IPID) under the Insurance Distribution Directive (IDD), page 5:

[...] the present EIOPA format limits or even prevents existing initiatives providing more radical consumer protection.

${ }^{24}$ The Association stated the following about the Dutch IPID (see Comments received by the Dutch Association of Insurers to EIOPA-CP-16-007: Consultation Paper on the proposal for the Implementing Technical Standards on a standardised presentation format of the Insurance Product Information Document (IPID) under the Insurance Distribution Directive (IDD), page 5 and 17):
}

They are based on a standard, recognizable format, differentiating from each product by showing the various cover elements. Individual insurance companies can indicate whether a certain specific element is covered, optional, or not covered.

and

Various consumer surveys show that consumers find product information the most important element. This information must be itemized and comparable. The Dutch Association of Insurers consequently determined that it is not sufficient to leave it to the provider to describe what is covered and what is not, but instead decided to define, together with a team of product specialists, the relevant product characteristics for a range of products. In the Dutch IPID the most relevant cover elements have their own icon and corresponding subtitle. 


\subsection{IPIDs in Practice}

\subsubsection{What Is Comparable Information?}

As set out above, the objective of IPIDs is to enable a customer to make an informed decision about insurance products by giving comparable standardised information. The question is whether the IPIDs meet this objective in practice. Therefore, the first question that needs to be addressed is, what can be understood by the concept of "comparable"?

The concept, in its pure form, must mean that if two or more insurance manufacturers produce products that are identical, then such manufacturers should also, in theory, produce IPIDs that are, in substance, identical (apart from details such as the name of the manufacturer and information about the company, which information by its very nature can be important for a customer as it enables the customer to retrieve additional information about the company, e.g. information about customer satisfaction and complaint statistics (to the extent such information is available). The same must apply if the coverage is statutory.

At the same time, if the insurance products are not identical, then the IPIDs will only satisfy the IDD's comparability objective if the insurance manufacturers have a uniform approach to setting out, for example, what are considered to be the "main features" of the coverage, or the extent to which the geographical scope of the coverage provided extends. For example, if one assumes that contents insurance includes, as standard, the right to counselling, then the information relating to counselling will only be comparable as between insurance products if all insurance providers list counselling in their IPID.

In practice, an insurer can treat information about a specific coverage in a number of different ways. For example, continuing with the example of counselling:

1. the insurer states whether counselling is covered in the IPID under either "What is insured?" or "What is not insured?" (both of which are mandatory headings required to be used in the IPID);

2. the insurer does not cover counselling and does not mention counselling in the IPID; or

3. the insurer covers counselling but does not mention counselling in the IPID.

The problem is obvious. Customers are only provided with an effective basis of comparison if all insurance providers adopt a consistent approach to informing customers whether or not, in this case, counselling is covered.

By way of illustration, take a scenario in which one insurance provider mentions in its IPID that the particular insurance product in question covers counselling, whilst another insurance provider does not mention counselling in its IPID at all. For a customer who considers it vital that counselling is covered, the only course of action open is to read the second insurance provider's underlying policy terms. That is the only way for such a customer to determine whether the failure by the second insurance provider to mention counselling in the IPID arises from the fact that such 
insurance provider does not actually cover counselling at all, or whether it is simply a case that the insurance provider has chosen not to emphasise counselling in its IPID.

Informing a customer, via an IPID, that one particular insurance provider does not provide particular coverage, in this case counselling, is valueless in terms of facilitating a comparison of products unless all the other insurance providers also state in their IPIDs whether such coverage is provided (regardless of whether, in this case, counselling is actually covered or not).

Such information, i.e. that particular coverage is provided by one insurance provider, is also valueless for comparison purposes if other insurance providers also provide the same coverage but have omitted such information from their IPIDs.

If all the insurance providers who are compared fail to mention anything about a particular coverage, in this case counselling, then a customer will have to read each insurance provider's underlying policy terms to determine whether such coverage is included by any, all or indeed none of the providers. In this scenario, the IPID regime has not assisted the customer in making an informed comparison between insurance products. On the other hand, it is arguable that the IPID regime has further exacerbated the problem of a customer believing that counselling was covered by one insurance provider, but not by others.

The examination in the following section illustrates that, as the IPID regime stands today, there is not necessarily a common understanding amongst insurance providers of what is actually needed for two or more IPIDs to be comparable.

\subsubsection{Examination of IPIDs}

\subsubsection{The Application of the Standardised Presentation Format in General}

Each of the IPIDs analysed by the authors complies with the requirement that the information presented be restricted to two A4 pages. Moreover, each such IPID has been designed in accordance with EIOPA's standardised presentation format, cf. Articles 1, 3 and 4 of the Implementing Regulation.

Save that insurer D and insurer E do not use a 'shield' in the icon next to the heading "How do I cancel the contract?" (as prescribed in Article 7(1)(h) of the Implementing Regulation), all the IPIDs are consistent with the standardised presentation format in the Annex to the Implementing Regulation, cf. Article 7(2) of the Implementing Regulation.

Moreover, in accordance with section 2 of the Implementing Regulation, all of the IPIDs state that the document only gives a general overview of the particular insurance product on offer, and that the customer is referred to the underlying policy terms for the complete pre-contractual and contractual information.

Ignoring the relevantly immaterial error regarding the 'shield', the design of the various IPIDs appears uniform and directly comparable. 


\subsubsection{Examination of Contents Insurance Products}

As described in Sect. 1.1, the following analysis and the analysis of the other insurance products in Sect. 3.3.2 is based on products from five different insurers. The analysis does not purport to cover the entirety of each IPID, but instead focusses on relevant similarities and differences. Where relevant to the analysis, the IPIDs are (for the sake of brevity) either quoted or summarised in respect of the most important similarities and differences identified by the authors (Table 1).

The analysis demonstrates that insurance providers often treat the same cover very differently.

For example in "What is this type of insurance?" insurer A very briefly mentions that contents insurance covers the property that the customer keeps in their home, whereas insurer B sets out examples of losses covered (fire, theft, etc.) and states that the insurance also includes third party liability insurance with a further option to extend coverage to electronics and bicycles.

An analysis of insurer A's policy terms shows that the contents insurance offered covers the customer's property in connection with for example fire, theft, etc., covers bicycles, includes third party liability insurance, and afford the customer an option to add a cover for electronics.

If a customer looks only at the initial description as set out in the IPIDs, they might suffer the misleading impression that insurer B provides more extensive coverage and offers a wider range of optional coverage as compared to insurer A.

In "What is insured?" all the IPIDs state that the customer's furniture and household effects are covered in the event of fire, theft and water damage, and that the insurance includes third party liability insurance and legal expenses insurance. Save for these consistent statements, there are no other overlaps between the particular cover that the various insurers have decided to highlight.

For example, insurers B, D and E state that their insurance covers counselling, whereas insurers $\mathrm{A}$ and $\mathrm{C}$ do not mention counselling at all. As regards insurer $\mathrm{A}$, such failure is arguable consistent with the underlying policy terms, which do not provide cover for counselling. However, as regards insurer $\mathrm{C}$, such failure is, arguably, inconsistent with the underlying policy terms which, upon analysis, reveal that counselling is within the scope of coverage insofar as it relates to travel. In this regard it is particularly notable that neither insurer A nor insurer $\mathrm{C}$ mentions counselling in "What is not insured?".

One sees a similar pattern in respect of identity theft, which is covered by insurers A, B, C and D, but not by Insurer E. Insurer E's failure to mention identity theft in "What is insured?" is consistent with its underlying policy terms, which do not provide coverage in respect of such risk. However, insurer E does not mention identity theft in "What is not insured?".

In its IPID, insurer E states that loss of, and damage to, luggage is covered, whereas insurer B states in its IPID that damage to luggage which occurs abroad is covered. Insurers A, C and D do not mention luggage in their IPIDs (whether as something which is within or without coverage). According to the insurers' 


\begin{tabular}{|c|c|c|c|c|}
\hline 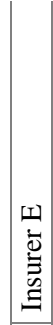 & 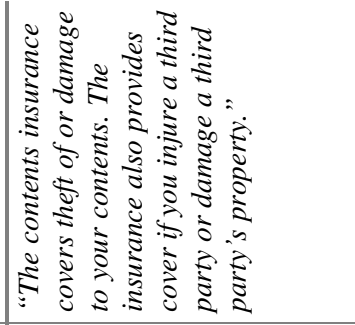 & 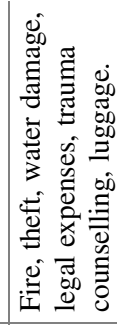 & 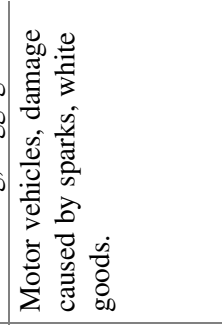 & 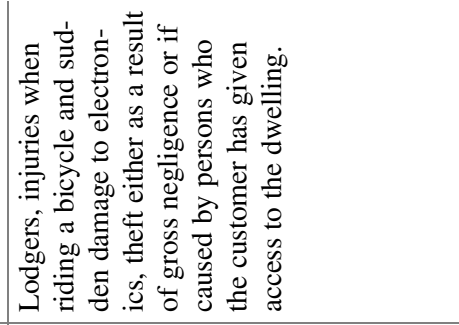 \\
\hline 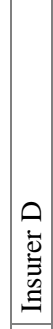 & 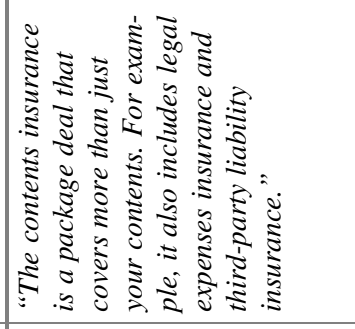 & 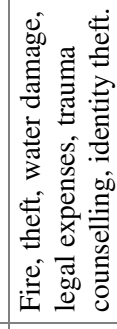 & 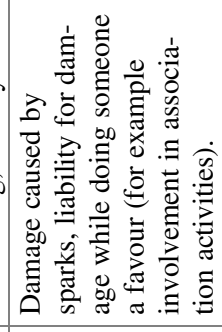 & 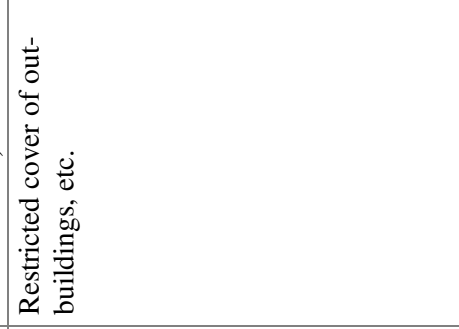 \\
\hline 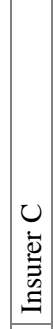 & 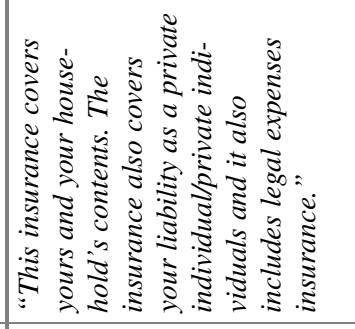 & 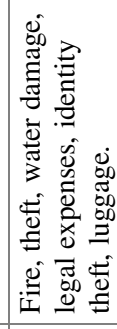 & 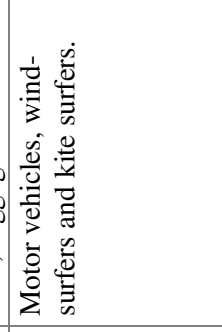 & 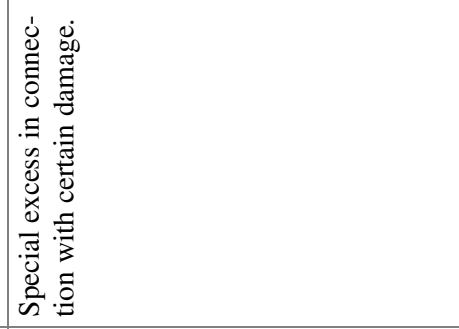 \\
\hline 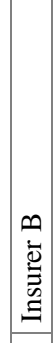 & 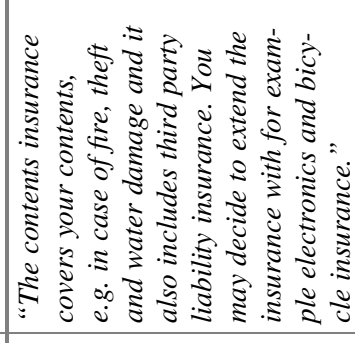 & 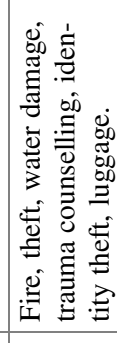 & 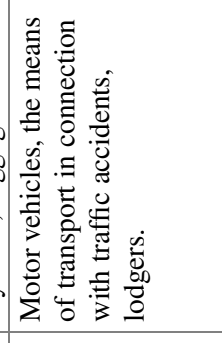 & 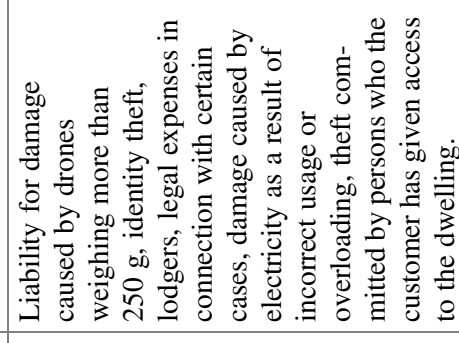 \\
\hline 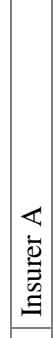 & 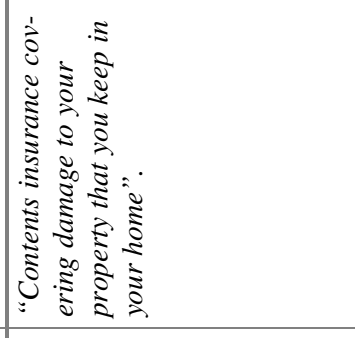 & 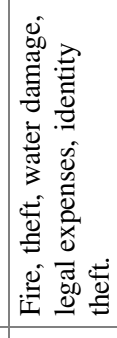 & 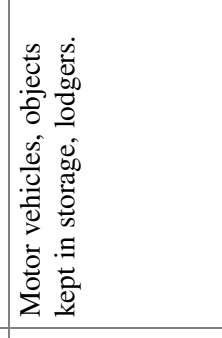 & 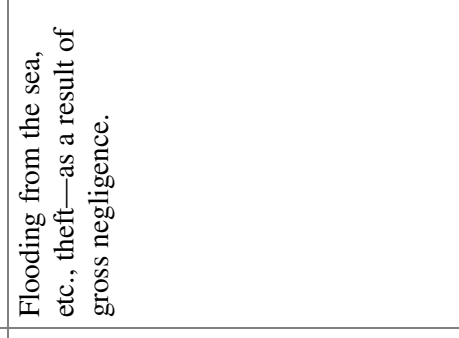 \\
\hline & 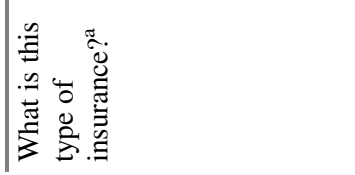 & 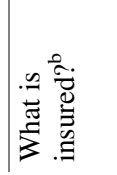 & 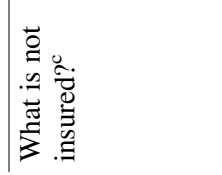 & 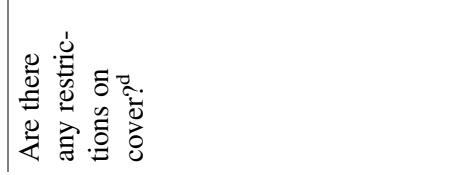 \\
\hline
\end{tabular}




\begin{tabular}{|c|c|c|}
\hline 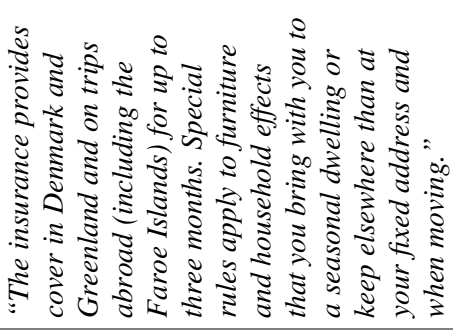 & 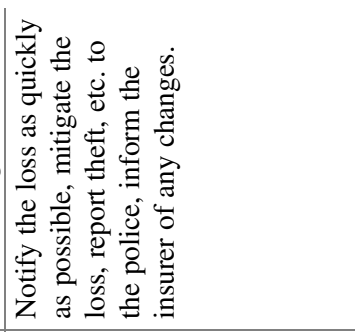 & 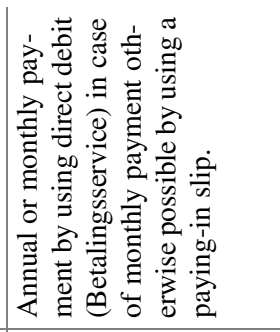 \\
\hline 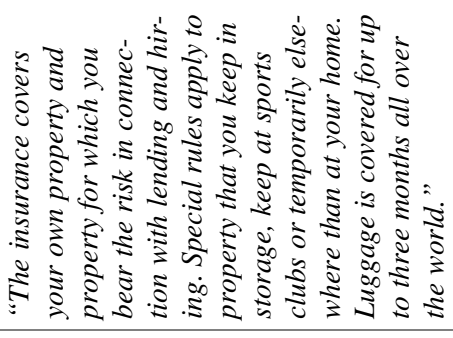 & 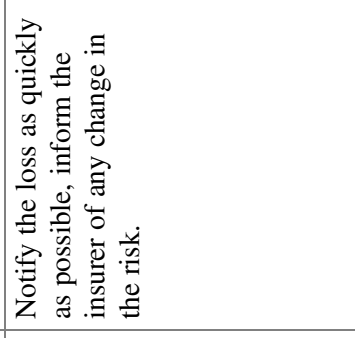 & 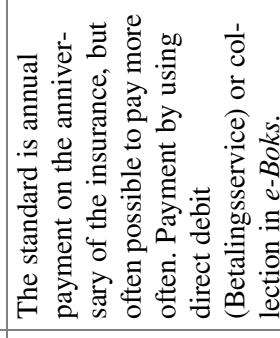 \\
\hline 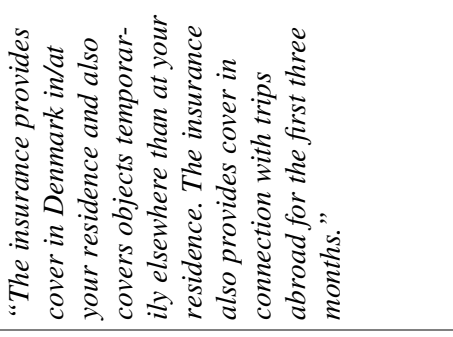 & 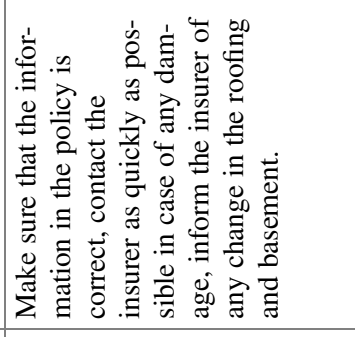 & 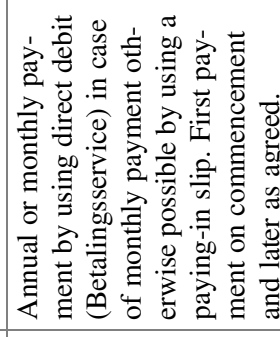 \\
\hline 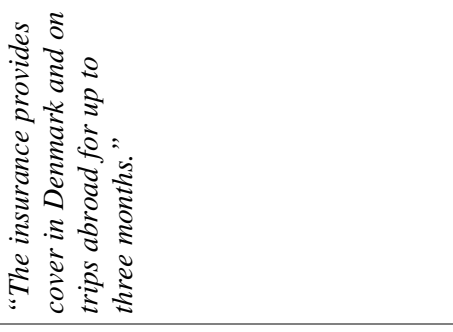 & 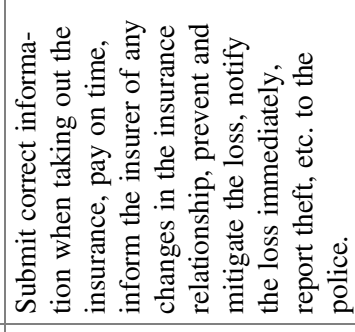 & 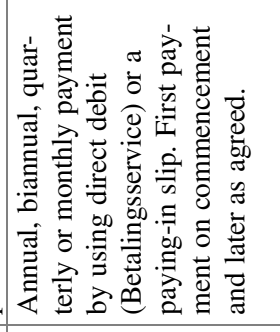 \\
\hline 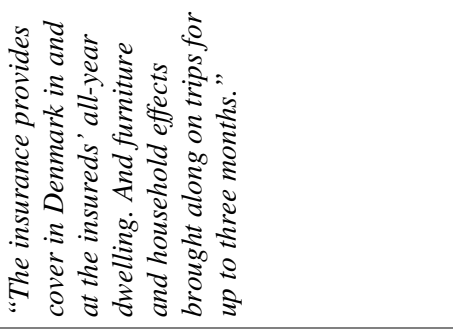 & 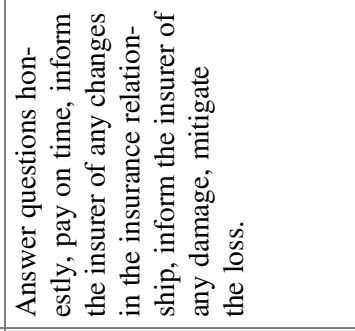 & 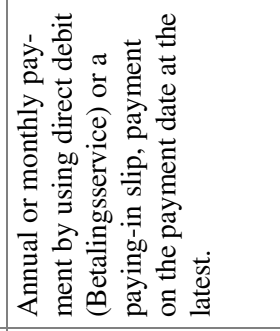 \\
\hline 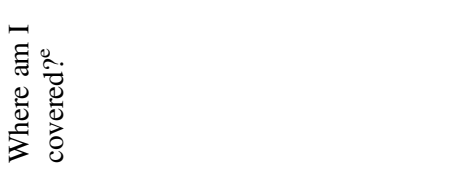 & 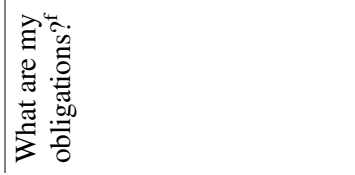 & 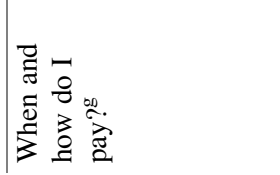 \\
\hline
\end{tabular}




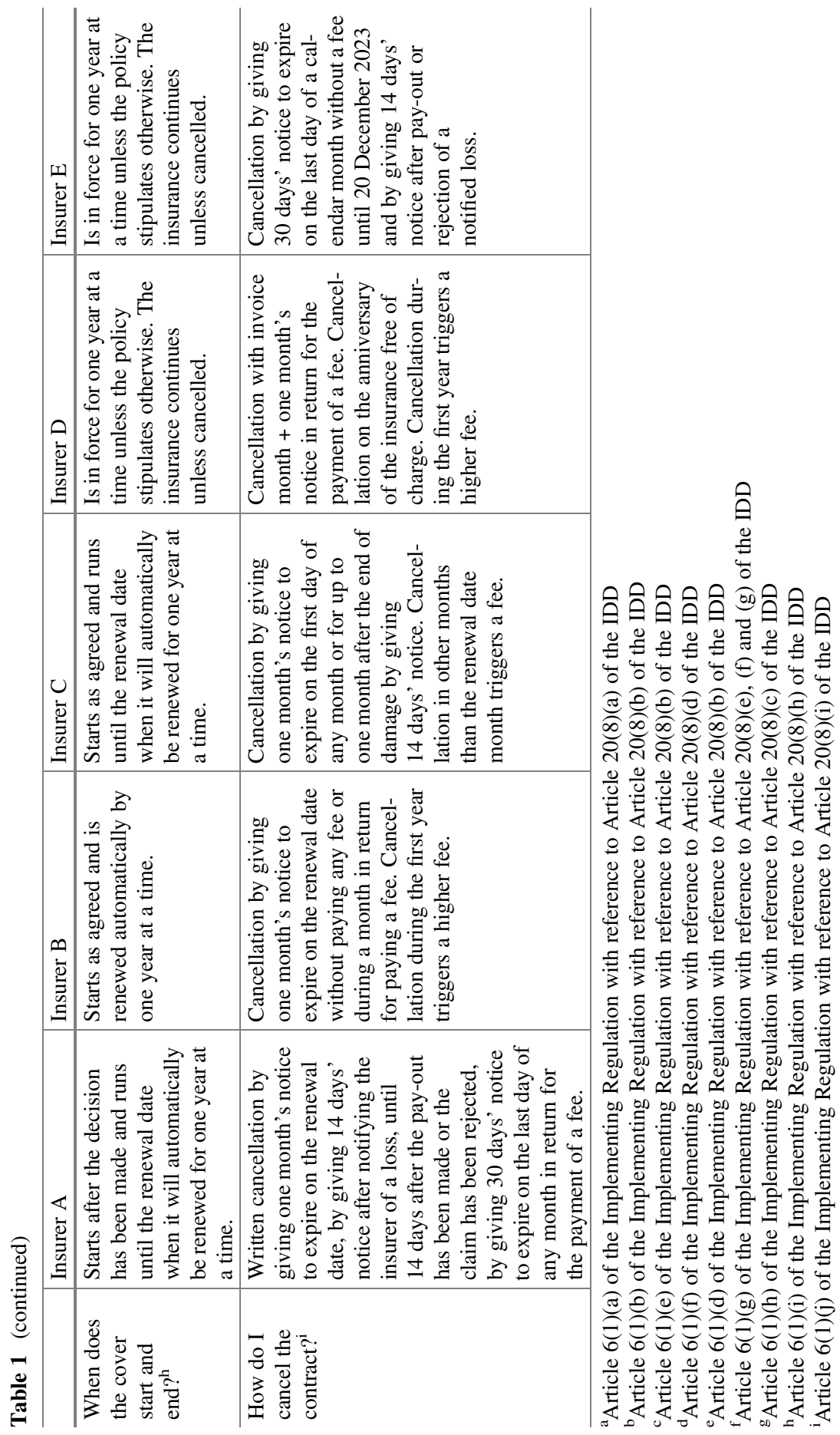


underlying policy terms, they all cover both loss of, and damage to, luggage. The scope for prospective customers being misled is obvious.

None of the various IPIDs examined adopt a consistent approach to listing exclusions under "What is not insured?".

Insurers A, B, C and E's IPIDs explicitly mention that motor vehicles are not covered. However, notwithstanding that its underlying policy terms state that motor vehicles are excluded from coverage, insurer D fails to explicitly state the same in its IPID. Once again, the scope for confusion is obvious. A prospective customer glancing over the IPID documents may well come to the conclusion that motor vehicle cover is only excluded if there is an explicit statement to that effect and thus be misled as to the extent of coverage under insurer D's policy. This is, of course, an extreme example, but it helps to illustrate the problem posed by inconsistency.

Further, the insurers have decided to emphasise (i.e. state explicitly within their IPID) very different exclusions. For example, insurer $\mathrm{C}$ states in its IPID that the insurance product does not cover windsurfers and kite surfers. According to underlying policy terms of the other insurers, insurers B, D and E, do cover windsurfers and kite surfers, whilst insurer A does not. It cannot, therefore, be deduced from the fact that insurer $\mathrm{C}$ has explicitly stated the relevant exclusion that the other insurers do actually cover windsurfers and kite surfers. As such, a customer requiring cover for windsurfing and kitesurfing would have to read the insurers' underlying policy terms in order to be able to perform a useful comparison. More problematically, perhaps, is the fact that, even then, one is assuming that the customer in fact realises that, despite the fact that an exclusion is not mentioned explicitly, it may still be present in the underlying policy terms. As with the exclusions as to vehicles set out above, the scope for confusion and for a customer to be potentially misled is plain.

The same applies to the exclusion relating to lodgers stated in insurer A's and insurer B's IPIDs. Lodgers are not explicitly listed under "What is not insured?" in the IPIDs produced by insurers C, D and E, but, according to those insurers' underlying policy terms, cover is not provided for lodgers. It should be noted, however, that lodgers are mentioned in insurer E's IPID, but the exclusion of coverage is set out under the heading "Are there any restrictions on cover?". Accordingly, customers are not able to simply compare the paragraphs in the IPIDs on a like-for-like basis as it is possible that coverage exclusions are set out either in "What is not insured?" or in "Are there any restrictions on cover?".

The simple conclusion is that, when comparing IPIDs, it cannot be deduced that an exclusion explicitly set out in one insurance provider's IPID, but not explicitly set out in a second insurance provider's IPID, is or is not applicable to the coverage provided by the second provider. It means that a prospective customer will have to consult the underlying policy terms to establish whether specific cover is in fact covered or excluded. More worryingly, perhaps, as set out above, that assumes that a prospective customer has the wherewithal to realise that just because one IPID explicitly sets out an exclusion and another IPID doesn't, that doesn't necessarily mean that the cover represented by the insurance product does not contain such exclusion. 
As demonstrated by the above examples, the insurers provide very different information in their IPIDs. An insurer failing to mention a specific risk as either being covered or not covered cannot be interpreted to mean that such risk is either covered or not covered. The problems presented when a customer reads a number of IPIDs, each of which is prepared with different emphasis and on an inconsistent (albeit compliant) basis are obvious; the customer will simply not have the information necessary to make an informed overall comparison. The customer will only be able to properly perform a comparison if they read further information, for example a detailed product sheet or the underlying policy terms.

There is also a significant difference between what the insurers have decided to mention in "Are there any restrictions on cover?". For example, insurer $\mathrm{C}$ is the only insurer that explicitly states in its IPID that theft is not covered in cases of gross negligence on the part of the insured. This is, however, an ordinary exclusion which, despite not being explicitly set out in any of the other insurance providers' IPIDs, is present in the underlying policy terms. Likewise, insurer E explicitly sets out in its IPID that the insurance does not cover theft in the customer's own home if the dwelling was not locked. Insurer D does explicitly set out this exclusion, but it is contained in "What is not insured?", rather than "Are there any restrictions on cover?". Insurers A, B and C do not set out such exclusions explicitly in their IPIDs, despite the fact that it is contained in the underlying policy terms.

Further, insurer A's IPID explicitly sets out the ordinary restriction that damage as a result of war, etc. is not covered. Perhaps unsurprisingly, the same restriction applies in respect of the cover offered by the other insurance providers, but this is only apparent from examining the underlying policy terms, as those providers do not set the restriction out in their IPIDs.

The simple conclusion is that it seems to be (at least from a customer's perspective) entirely a matter of chance as to what risks are or are not explicitly set out as covered, excluded or a subject to a restriction on cover in the IPIDs relating to contents insurance products. The consequence is that a customer is not able to effectively compare the overall cover provided by the contents insurance products by simply analysing the IPIDs, notwithstanding the fact that the insurance underlying policy terms are, to a significant degree, consistent in terms of cover, exclusions and restrictions.

In "Where am I covered?" the various insurance providers describe the geographical area of cover using phrases that do not lend themselves to easy comprehension by a prospective customer. As such, there is obvious scope for confusion amongst customers as to whether all the contents insurance products actually have the same geographical area of cover. This is despite the fact that, upon examination of each set of underlying policy terms, it is apparent that all of the insurance products have essentially the same geographical area of cover.

For example, insurer B states very briefly in its IPID that the insurance provides cover in Denmark and on trips abroad for up to three months. Upon examining the underlying policy terms, it is apparent that insurance provides cover in Denmark, with the exception of the Faroe Islands and Greenland, and only if the customer's furniture and household effects are in or at the customer's all-year dwelling, in a 
safe-deposit box, in a warehouse, removal van or container, or in the customer's spouse's or cohabitee's sheltered dwelling. Special rules also apply in connection with furniture and household effects in a seasonal dwelling, those temporarily kept elsewhere than at the customer's all-year dwelling, and those effects purchased abroad and repatriated to Denmark.

By comparison, insurer E states in its IPID that the insurance provides cover in Denmark and Greenland and during trips of a duration of three months abroad (including trips to the Faroe Islands) and that special rules apply to furniture and household effects that the customer brings with them to their seasonal dwelling. Besides the fact that insurer E' policy provides cover in Greenland on the same terms as in Denmark, it is essentially to insurer B's policy. However, this is difficult to deduce from the relevant IPIDs. Insurer B has dealt only with geographical scope of cover, whereas insurer $\mathrm{E}$ has gone a step further and also deals with the difference between an all-year dwelling and a seasonal dwelling. A customer comparing the two IPIDs might therefore be led to believe (incorrectly) that insurer B provides more extensive cover than insurer E.

Under "What are my obligations?" all the insurance providers state that the customer must inform the insurer of any changes in the insurance relationship. This is variously stated as providing that the customer must "[...] notify us", "[...] contact us if the information in the policy is incorrect", "[...] inform us of any changes", "[...] inform us of any changes in your risk", or "[...] make sure that the information in your policy is correct", etc. Notwithstanding the slight variation in language used, the content and extent of the obligation remains clear and is able to be easily comprehended and thus easily comparable.

The same applies to the requirements regarding notification of loss where the customer must contact the insurers either "as quickly as possible" (insurers C, D and E), "immediately" (insurer B), or simply required to "inform" the insurance provider (insurer A).

Some insurance providers also stipulate that the customer must pay on time (insurers $\mathrm{A}$ and $\mathrm{B}$ ), that the customer must mitigate the loss (insurers $\mathrm{A}, \mathrm{B}$ and $\mathrm{E}$ ) and that losses relating to criminal acts, for example theft, must be reported to the police (insurers B, D and E). What is notable is that despite the fact that not all of the insurance providers list these various obligations in their IPIDs, each set of underlying policy terms contains all of the various obligations. In short, the customer must comply with essentially the same obligations no matter which insurance policy is taken out, however that fact cannot be directly deduced from a comparison of the insurance providers' various IPIDs.

In "When and how do I pay?", "When does the cover start and end?" and "How do I cancel the contract?", the insurance providers provide the same information. Even though the wording utilised is not always the same, all of the insurance providers state, for example, whether it is possible to pay annually, biannually, quarterly or monthly; when the first payment is to be made; and that it is possible to pay by using direct debit (in Danish: Betalingsservice) or a paying-in slip. Such is the case for the remaining two headings analysed. Under both headings, the insurance providers have taken a consistent approach when choosing which information to include. 
Accordingly, in this regard at least, the IPIDs act as an effective tool for comparison as the information that the insurance providers have chosen to emphasise in their IPIDs completely overlaps.

\subsubsection{Examination of Compulsory Third Person Motor Liability Insurance}

The Danish Road Traffic Act stipulates that the owner or user of a motor vehicle in Denmark must have insurance. ${ }^{25}$ The insurance must provide cover for compensation in respect of damage to property and injuries to persons caused by the vehicle and coverage limits are subject to various fixed amounts laid down by law (Table 2).

As was the case with contents insurance, a comparison of the IPIDs produced for third person motor liability insurance reveals that insurance providers often deal with the same elements differently.

In "What is this type of insurance?", the insurance providers set out the contents of third person motor liability insurance with varying degrees of detail. For example, on the one hand insurer A states very briefly that the insurance provides cover if the customer's car is involved in an accident. On the other hand, insurer D states that the insurance covers third party liabilities and loss of, or damage to, the customer's motorcar, which cover can be supplemented by various add-ons. Insurer D also describes the rules for when a customer is able to take out no-claims driver insurance (in Danish: elitebilistforsikring) or "standstill insurance". Insurers B, C and E all refer to the fact that third party liability insurance is compulsory and, together with insurer D, further mention that it is possible to supplement the compulsory insurance with various add-ons.

As third person motor liability insurance is compulsory in Denmark, the main features are by definition the same. If only the main features were described, the IPIDs should, in principle, be identical. However, in practice, that is not the case. As illustrated above, the majority of the IPIDs analysed state, for example, that the compulsory insurance may be supplemented by add-ons and go on to describe such add-ons. This is, perhaps, unsurprising. Insurance providers are likely to be keen to distinguish their products from their competitors and are thus likely to be reluctant to mention only the bare minimum mandatory cover.

The information provided in the IPIDs under "What is insured?" varies significantly. For example, insurer E lists the cover that can be selected, including "third party liability insurance" without describing what the insurance actually covers. Insurers A, B and D, on the other hand, state that the third-party liability insurance provides cover for personal injury and damage caused to, respectively, third parties and their property by the customer's car. Insurer $\mathrm{C}$ adopts a further alternative approach and sets out the specific limits of cover, including that in respect of damage to the car and its equipment, but without, however, making clear that the cover for

\footnotetext{
${ }^{25}$ Section 105 of Danish Consolidated Act no 1324 of 21 November 2018, the Road Traffic Act (in Danish: færdselsloven).
} 


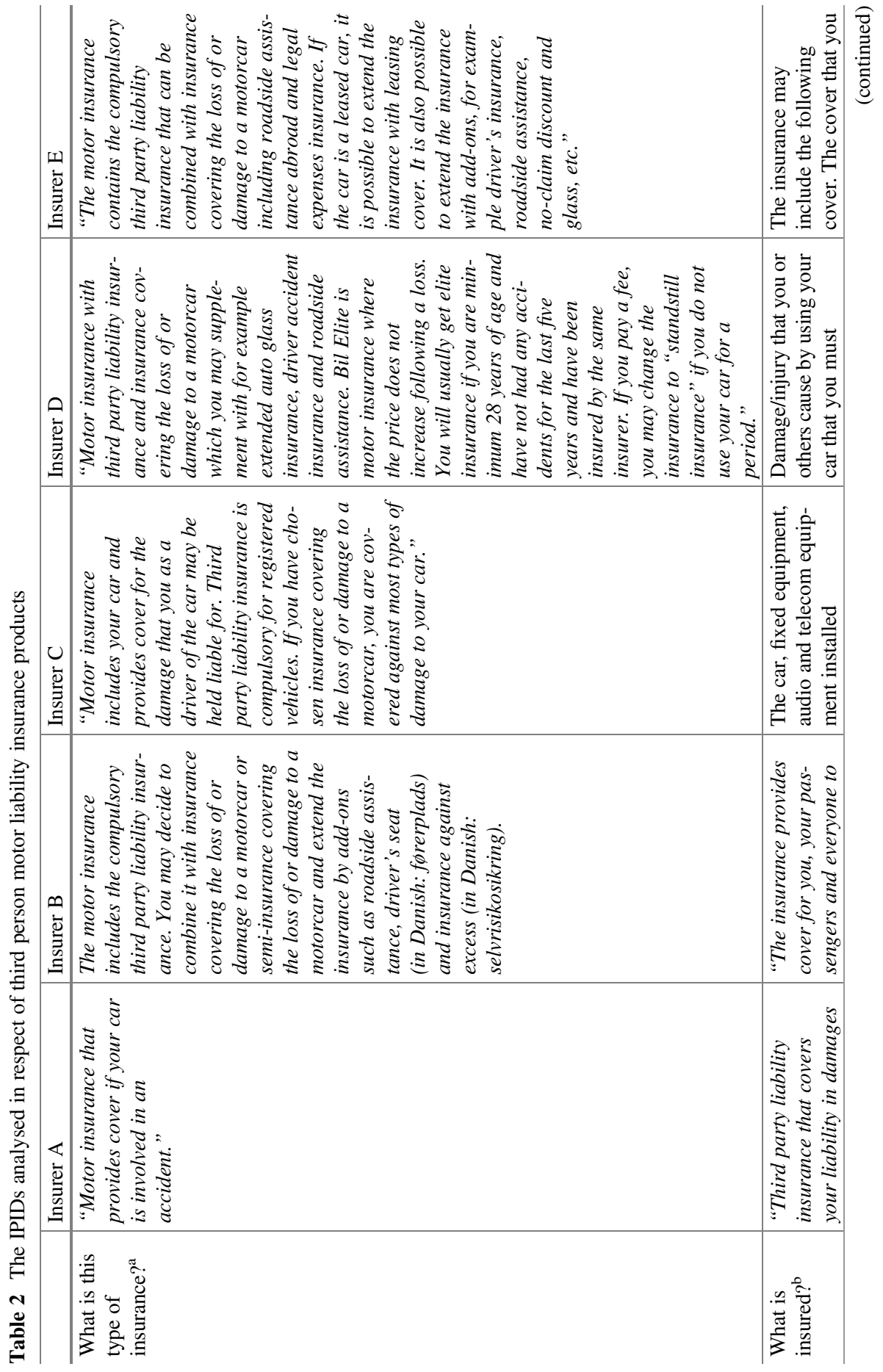




\begin{tabular}{|c|c|c|c|}
\hline 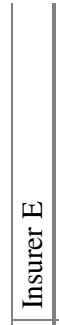 & 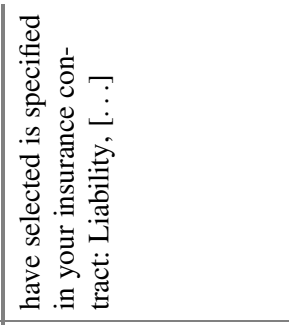 & 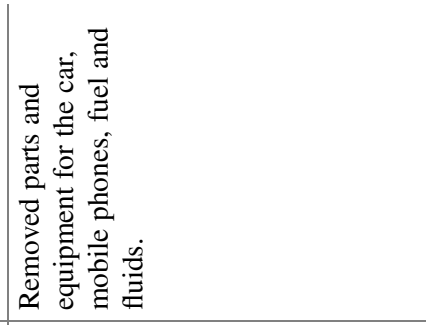 & 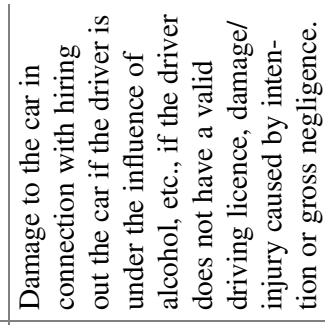 \\
\hline \begin{tabular}{|} 
\\
0 \\
$\overrightarrow{0}$ \\
$\overline{0}$ \\
$\underline{a}$ \\
\end{tabular} & 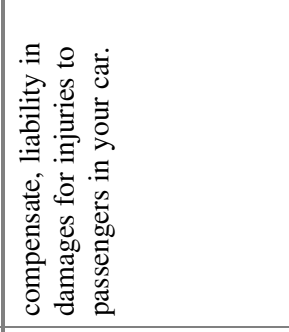 & 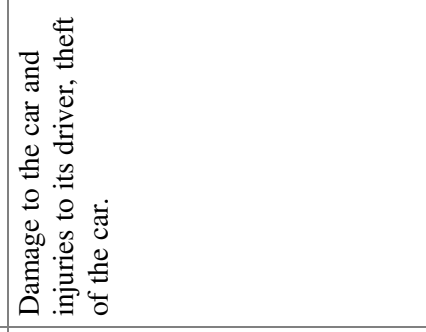 & 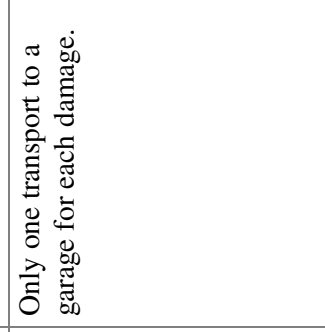 \\
\hline 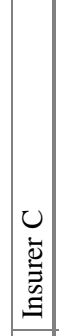 & 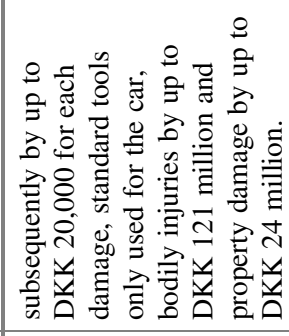 & 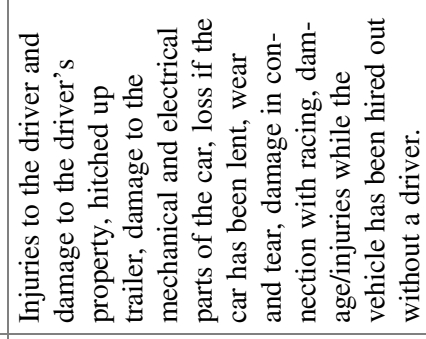 & 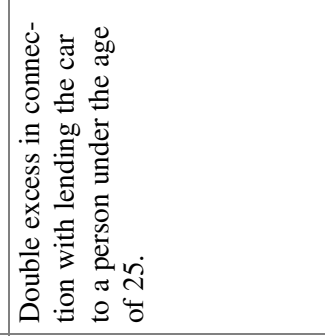 \\
\hline 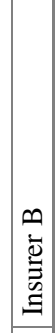 & 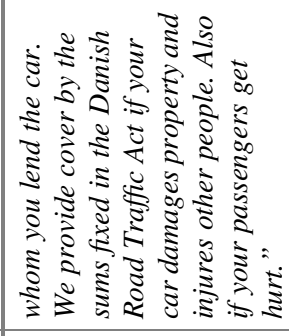 & 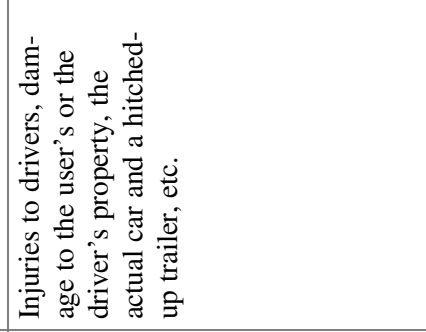 & 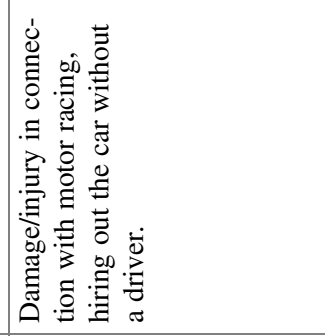 \\
\hline $\begin{array}{l}\varangle \\
\overleftrightarrow{D} \\
\vdots \\
\vdots \\
\vdots \\
\end{array}$ & 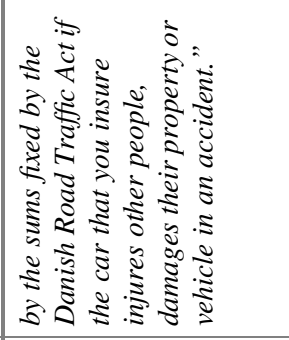 & 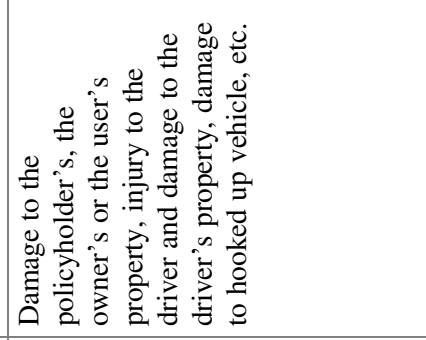 & 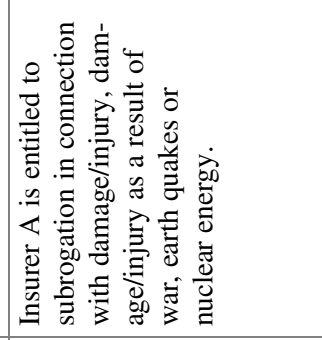 \\
\hline & & 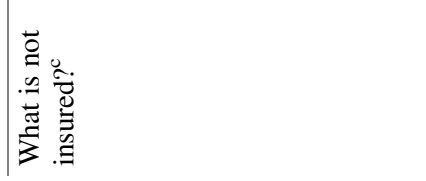 & 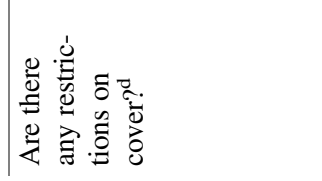 \\
\hline
\end{tabular}




\begin{tabular}{|c|c|c|c|}
\hline 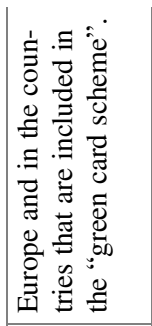 & 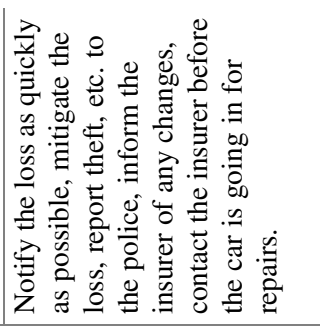 & 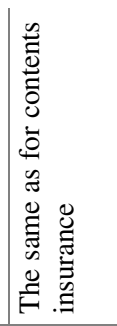 & 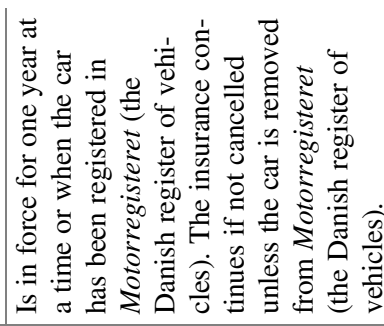 \\
\hline 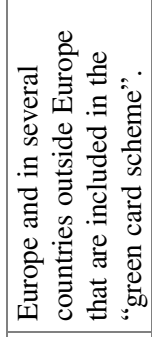 & 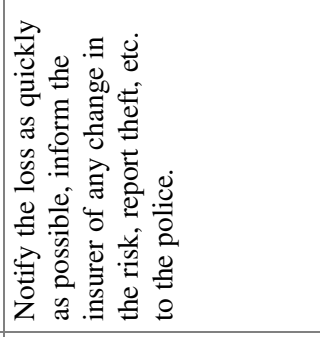 & 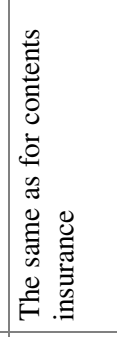 & 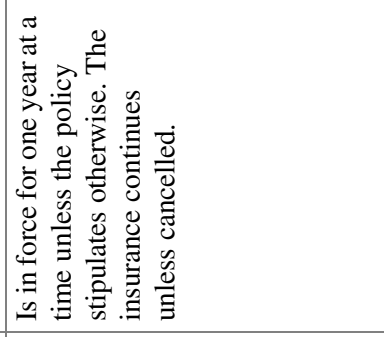 \\
\hline 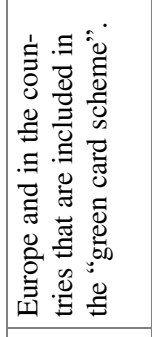 & 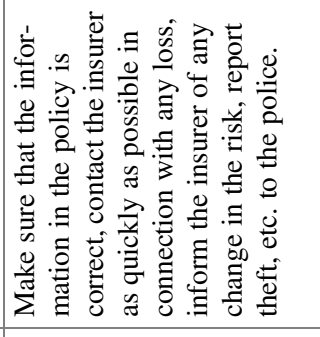 & 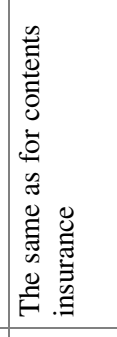 & 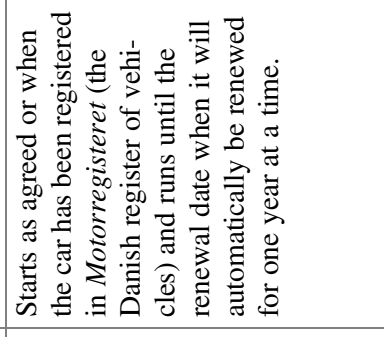 \\
\hline 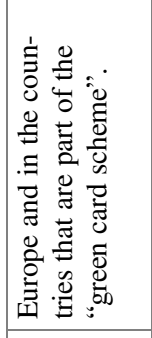 & 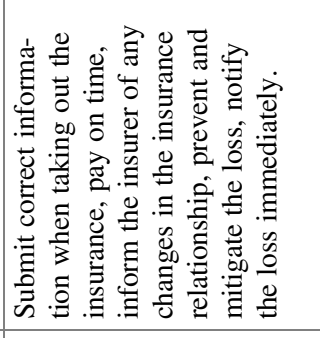 & 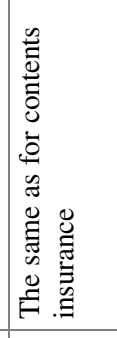 & 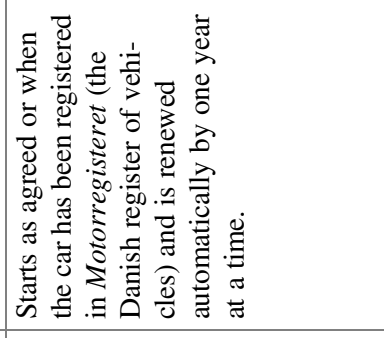 \\
\hline 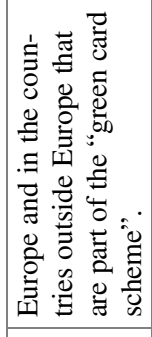 & 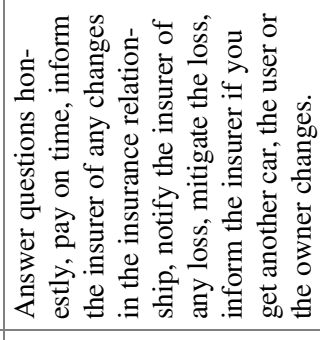 & 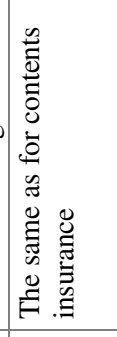 & 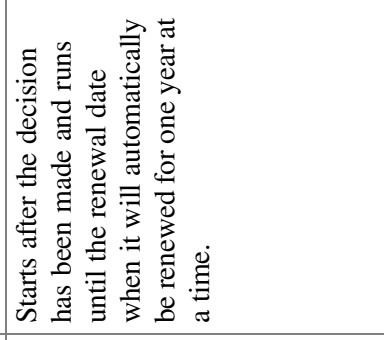 \\
\hline 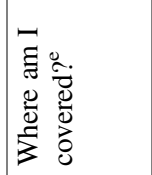 & 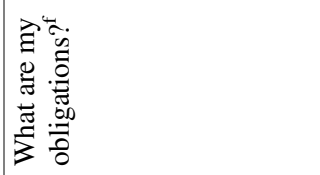 & 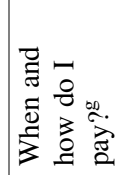 & 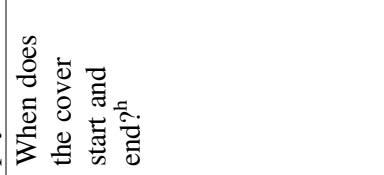 \\
\hline
\end{tabular}




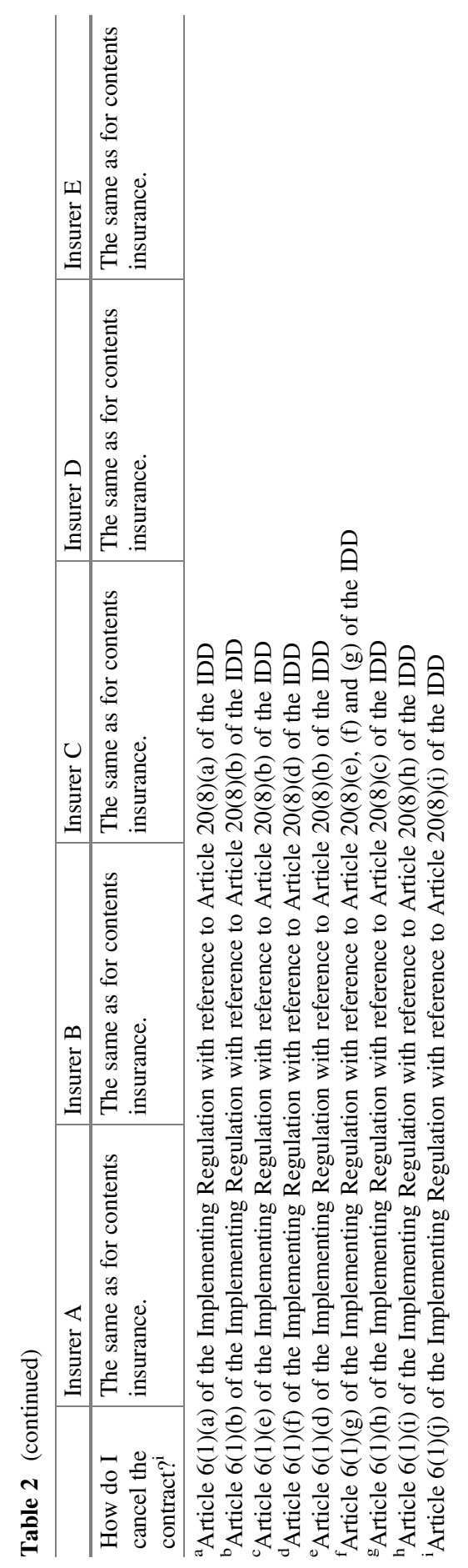


the car and its equipment is conditional on attaching the relevant add-on to the policy (i.e. that add-on covering loss of, or damage to, a motorcar).

However, what is not clear from the IPIDs is the fact that the scope of cover afforded by third party liability insurance is, given its compulsory nature, governed by statute. That lack of clarity arises because a number of the insurance providers set out more information about their insurance covering loss of, or damage to, a motorcar and add-ons than they do about the actual scope of third person motor liability insurance. From an insurance manufacturer's point of view this is understandable; they want to distinguish their products beyond the bare minimum statutorily required cover. However, considering the object of the IPIDs and their current standardised format it is not necessarily appropriate or in line with the regulation.

In "What is not insured?" the insurance providers have a tendency to mention exclusions that are relevant to their optional insurance covering, for example, the loss of, or damage to, a motorcar, and various other add-ons instead of the exclusions applicable to the mandatory third-party motor liability insurance. In theory these exclusions also apply to the third party liability insurance, but it is debatable whether it is relevant to a customer (who must take out the compulsory third person motor liability insurance) to know that such insurance does not cover damage to the car in connection with, for example, racing (as mentioned by insurer C) as third party liability insurance generally does not cover any damage to the car at all.

Insurer $\mathrm{D}$ is the only insurer that has divided the exclusions into sub-headings. Insurer D states under the sub-heading relating to third party motor liability insurance that damage to the car and injuries to its driver as well as theft of the car are not covered. Insurer A states that the insurance offered does not cover damage to the policyholder's, the owner's, the driver's or the user's property, whereas insurer B states only that the user's and the driver's property is not covered. Insurer C states that the driver's property is not covered, and insurer E does not mention anything about the driver's or the user's property.

Notwithstanding the inconsistent approach of the various insurance providers as set out above, upon examination of the various underlying policy terms, it becomes apparent (perhaps unsurprisingly) that each insurance policy offered in fact has the same exclusions relating to damage to property belonging to the owner, the driver, the user and the policyholder, injuries to the driver and damage to a vehicle being towed.

Even though the cover is for all intents and purposes the same, the IPIDs do not give this impression. Instead, the insurance providers have decided to set out information relevant to their particular add-ons, which allows them to distinguish themselves from the others. Moreover, in some of the IPIDs, it is not entirely clear if the cover or the exclusion relates to the compulsory third party liability insurance or the optional add-ons, something which it is, obviously, important for a prospective customer to know.

There is also some difference between the information that the insurance providers have included in their IPIDs under the heading "Are there any restrictions on cover?". Only insurer A mentions that it has a right of subrogation and that damage in connection with war, etc. is excluded. This is despite the fact that such restrictions 
are present in all of the insurance providers' underlying policy terms in respect of both the third-party liability insurance and any add-ons. The same applies to use of a car for racing (as mentioned by insurer B) and to damage in connection with hiring out the vehicle (as mentioned by insurers $\mathrm{B}$ and $\mathrm{E}$ ).

Once again, the restrictions on the cover are the same, but they are dealt with and described differently in the insurance providers' IPIDs.

In "Where am I covered?" the insurance providers take differing approaches to describing the geographical scope of coverage notwithstanding the fact that, upon examination of the underlying policy terms, such geographical scope is identical across the policies. So, insurers A, D and E state that the insurance provides cover in Europe and in the countries outside Europe that are part of the "green card scheme", whereas insurers B and C state that the insurance provides cover in Denmark and in the countries that are part of the "green card scheme".

The geographical area of cover is exactly the same in all the policies, each and every European country being part of the "green card scheme". However, if the prospective customer does not know which countries are part of the "green card scheme" (something well within the realms of possibility), the difference in the wording used in the IPIDs might cause the customer conclude that some countries in Europe are not part of the scheme or that the area of cover of insurers A, D and E is broader than that of insurers B and $\mathrm{C}$.

The content under the headings "What are my obligations?", "When and how do I pay?", "When does the cover start and end?" and "How do I cancel the contract?" is essentially the same as the content contained in the contents insurance analysed in Sect. 3.3.2.2.

\subsubsection{Examination of Compulsory Workers' Compensation Insurance}

The Danish Workers' Compensation Act stipulates that employers in Denmark are under an obligation to insure their employees and transfer their risk of accidents to an insurer. $^{26}$ The insurance is voluntary for self-employed persons and assisting spouses. The insurance must provide some specified benefits in connection with bodily injuries caused by accidents at work (Table 3 ).

As workers' compensation insurance is compulsory, all the insurance products include the same basic cover, i.e. the benefits listed in the Danish Workers' Compensation Act, for injuries sustained as a consequence of work. Disregarding any add-ons, the IPIDs should, in theory, be more or less identical.

However, as with contents insurance and third-party motor liability insurance, the analysis of the IPIDs for workers' compensation insurance demonstrates that the insurance providers often deal with the same aspect of the cover differently.

\footnotetext{
${ }^{26}$ Section 50 of Danish Consolidated Act no 216 of 27 February 2017, Workers' Compensation Act (in Danish: arbejdsskadesikringsloven).
} 


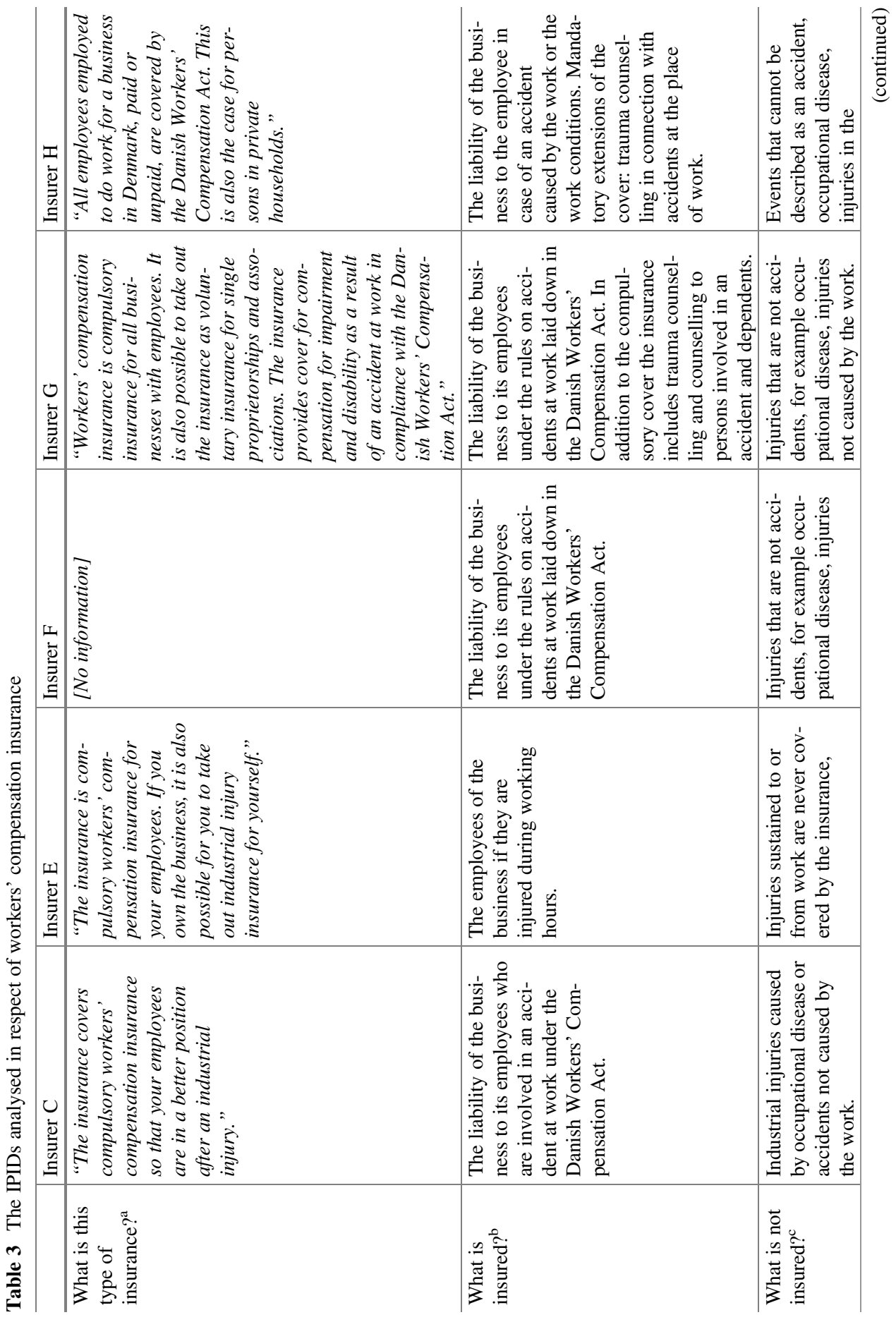




\begin{tabular}{|c|c|c|c|c|}
\hline & 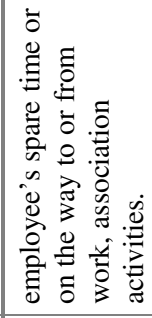 & 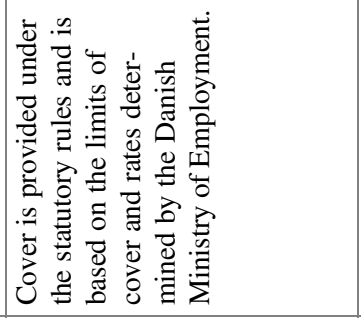 & 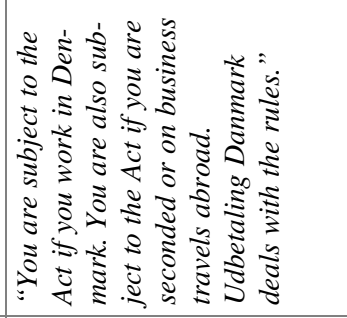 & 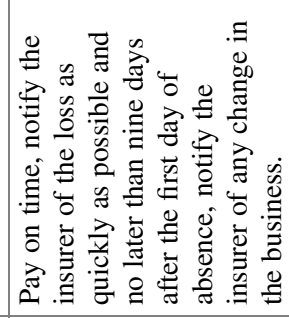 \\
\hline 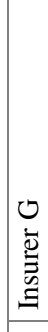 & & 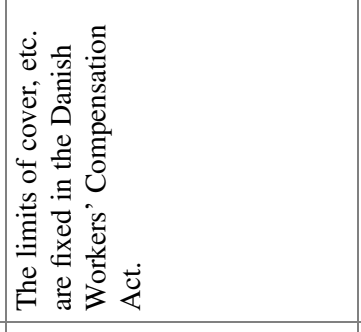 & 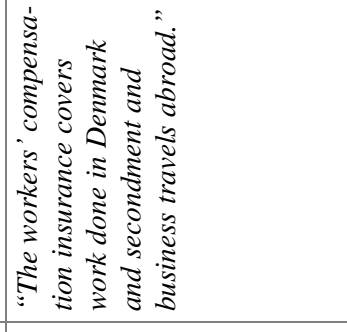 & 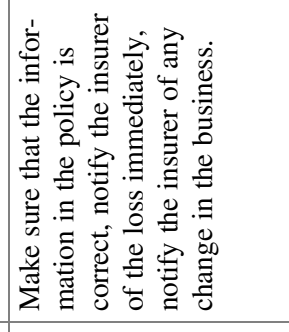 \\
\hline 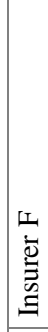 & 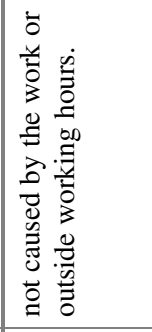 & 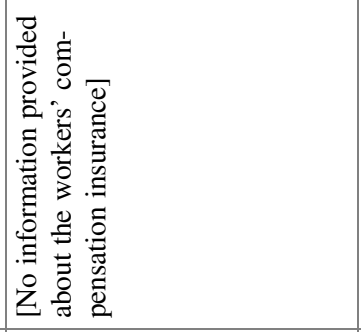 & 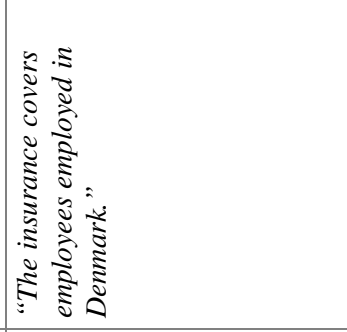 & 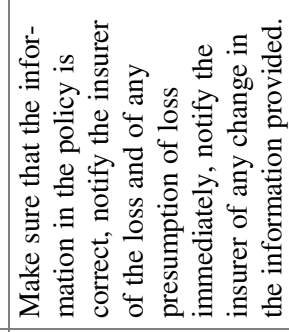 \\
\hline 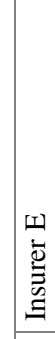 & 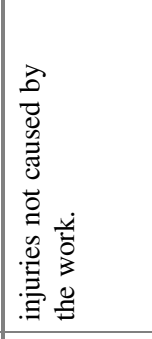 & 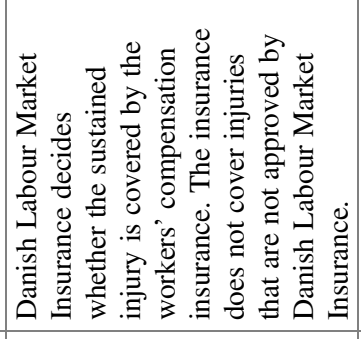 & 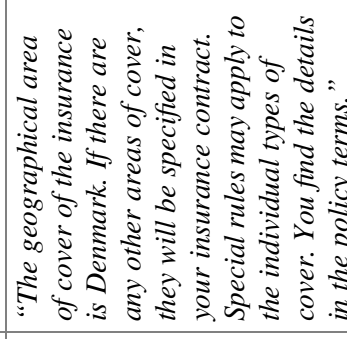 & 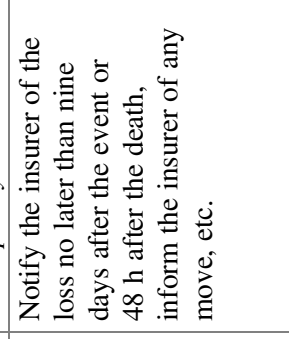 \\
\hline 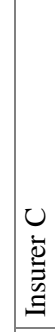 & & 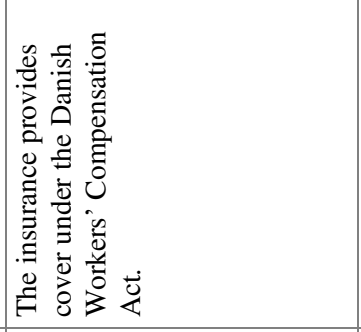 & 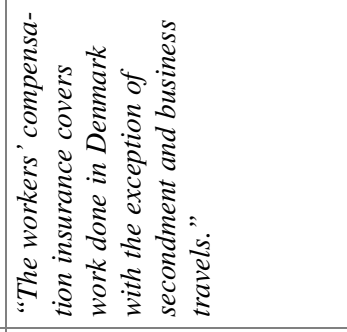 & 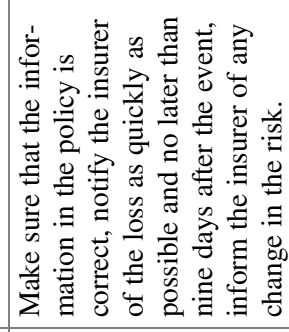 \\
\hline & & 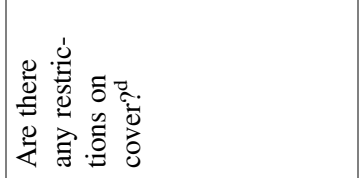 & 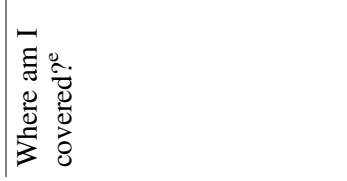 & 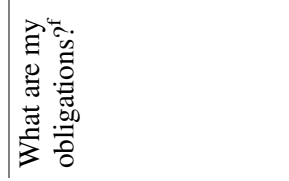 \\
\hline
\end{tabular}




\begin{tabular}{|c|c|}
\hline 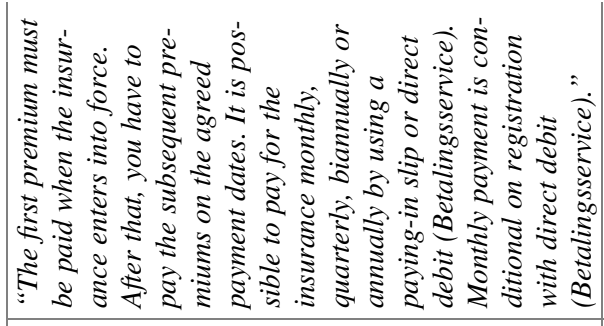 & 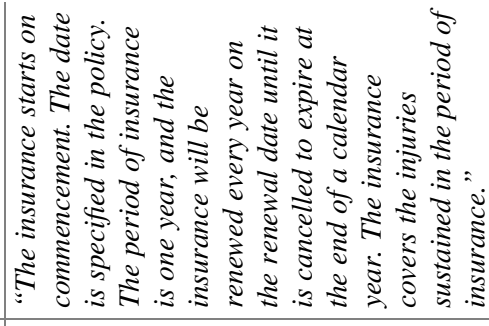 \\
\hline 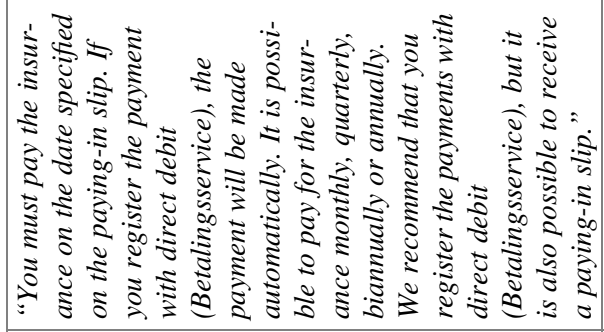 & 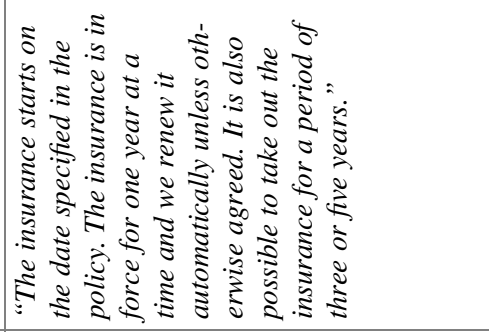 \\
\hline 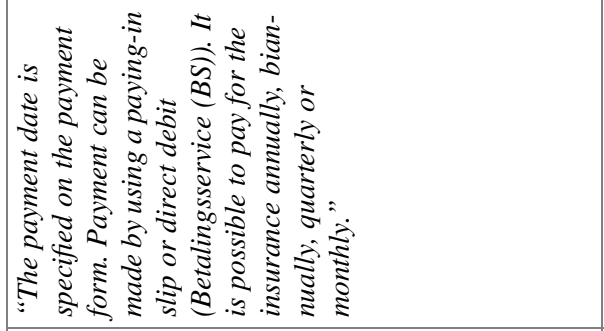 & 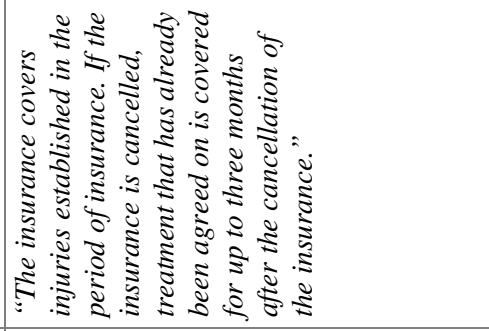 \\
\hline 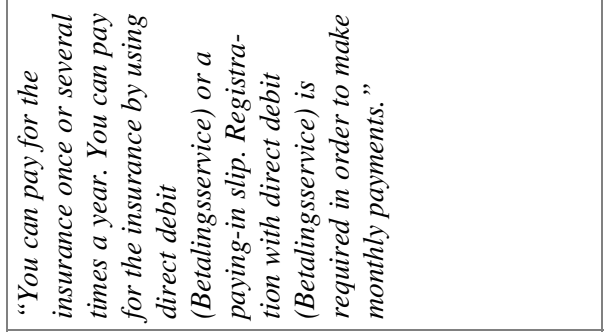 & 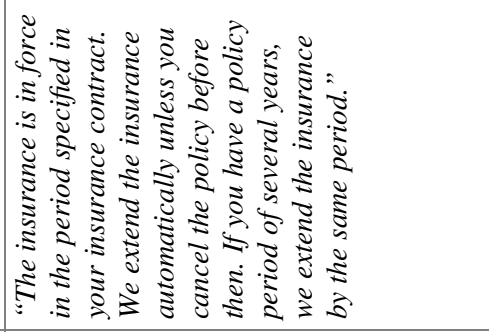 \\
\hline 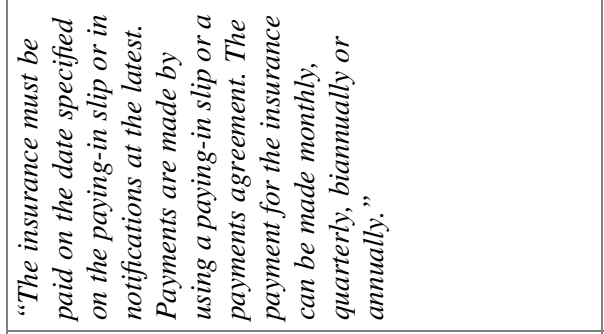 & 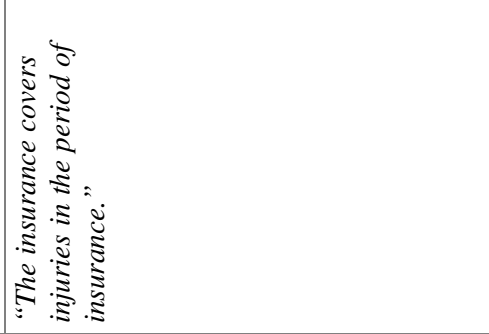 \\
\hline 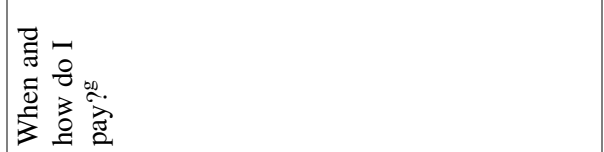 & 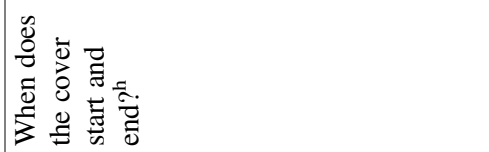 \\
\hline
\end{tabular}




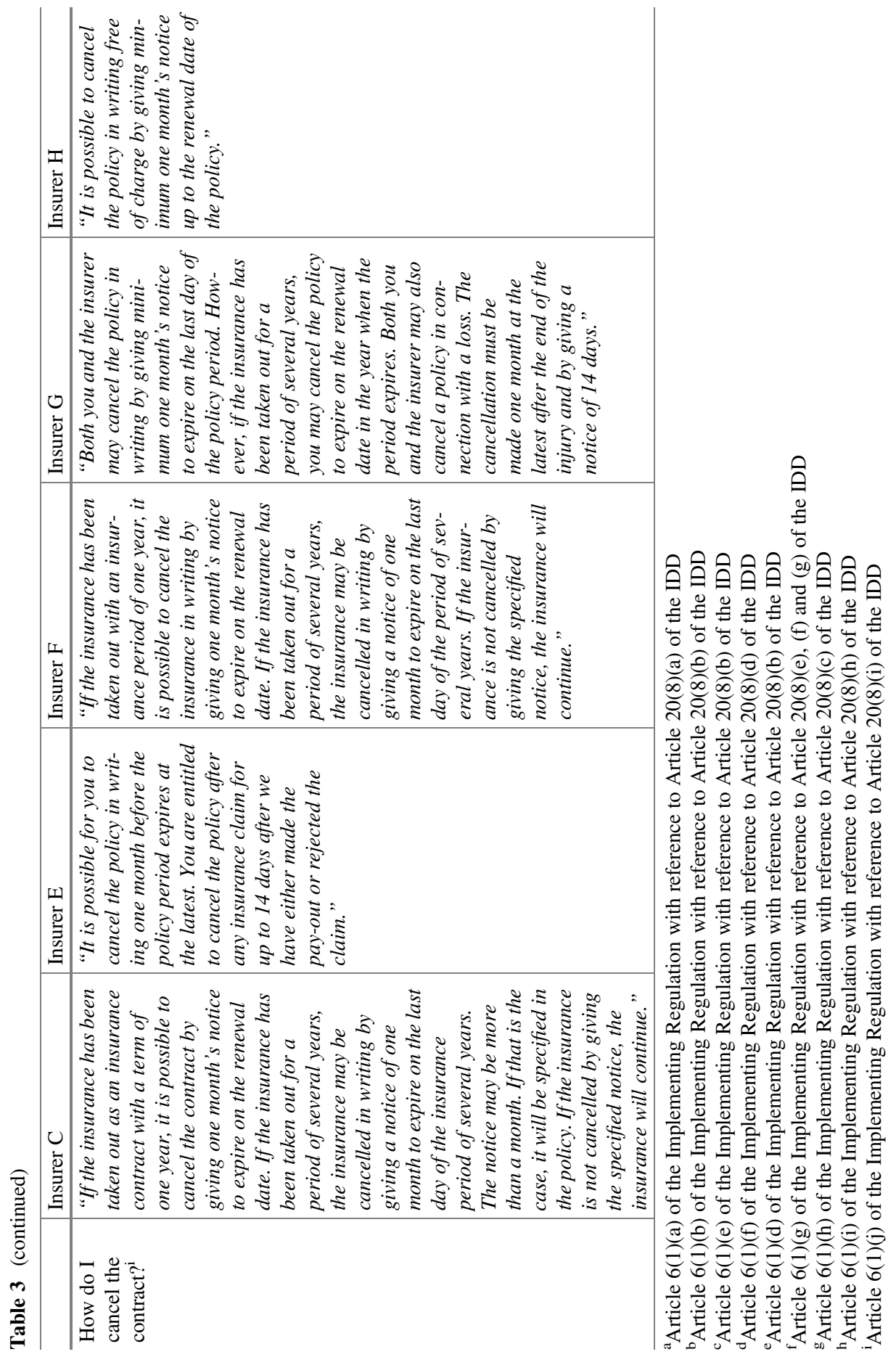


In "What is this type of insurance?" insurers C, E and G state that workers' compensation insurance is compulsory. Insurer $\mathrm{F}$ has not included this heading in its IPID. Insurer $\mathrm{H}$ (incorrectly) states that all employees are subject to the Danish Workers' Compensation Act without giving any other information about the insurance. Insurers $\mathrm{E}$ and $\mathrm{G}$ mention various add-ons in the description.

In "What is insured?", insurers C, F, G and H refer to the Danish Workers' Compensation Act and all the insurance providers list the benefits covered under the Act, including medical treatment expenses and compensation for the loss of the ability to work. The information about the cover provided by all the insurance providers is all-but identical.

In addition to the compulsory benefits, insurer $\mathrm{G}$ states that counselling (which is not a compulsory benefit) is covered. Insurer G, therefore, has decided to highlight the fact that it has extended coverage beyond the compulsory minimum. Insurer $\mathrm{H}$ states that counselling is a compulsory extension of its cover.

Overall, the information set out in each IPID under the heading "What is insured?" is comparable.

In "What is not insured?" insurers C, F, G and $\mathrm{H}$ state that occupational disease is excluded from the cover offered. Insurers C, E, F and G state that injury not actually caused by work is excluded just as insurers $\mathrm{E}$ and $\mathrm{H}$ mention that injury sustained on an employee's journey to or from work is not covered.

The Danish Workers' Compensation Act only provides for an obligation to insure employees in connection with industrial accidents. It does not impose an obligation to insure against occupation disease because, historically, occupational disease has not been considered to be an insurable risk in Denmark. The same applies to injuries not sustained as a result of work, including injuries sustained during the employee's journey to and from work, as such injuries are not within the scope of the Act, not having been a direct result of the employee's work or the conditions under which the work is performed.

However, it is difficult to see, based on the insurance providers' IPIDs, that all of the underlying policies are subject to the same (statutory) exclusions because the insurance providers choose to emphasise different exclusions. As such, the basis of comparison is distorted. If one insurance provider decides to mention that occupational disease is excluded, whereas another insurer does not mention such exclusion, the scope for confusion when one is comparing the IPIDs is obvious.

In "Are there any restrictions on cover?" insurer F only sets out the restrictions relating to the add-ons it offers in respect of its cover, whereas insurers $\mathrm{C}, \mathrm{E}, \mathrm{G}$ and $\mathrm{H}$ all state simply that the cover is provided under the Danish Workers' Compensation Act. This differing approach is adopted despite the fact that, substantively, there is no difference between the cover offered by the insurance providers.

In "Where am I covered?" there is a significant difference between what some of the insurance providers state as the geographical area of cover. Insurer H's wording addresses the employee (even though it is the employer that is under an obligation to take out insurance) and states that "you" are covered if the work is performed in Denmark or are seconded or on business travels abroad. Insurer G's description of the area of cover is identical to the description provided by insurer $\mathrm{H}$, whereas 
insurer $\mathrm{F}$ states that the insurance covers employees employed in Denmark. In its IPID, insurer $\mathrm{C}$ describes the geographical area of cover as being Denmark, with the exception of secondment and business travels. It is unclear whether insurer C's IPID means that the insurance provides cover in Denmark but not if the employee is on business travels or seconded from abroad to Denmark, or whether the insurance provides cover in Denmark and abroad if you are on a business trip or have been seconded from Denmark. The relevant underlying policy terms simply refer to the rules laid down in the Danish Workers' Compensation Act. It is, of course, not the format of the IPID that has made insurer C's description unclear, but rather the wording that insurer $\mathrm{C}$ has adopted. Such example clearly illustrates the insurance provider's differing approaches to providing a piece of information which should, in theory, be identical for all of them (because it should correspond exactly to what is set out in the Danish Workers' Compensation Act and the regulations about the coordination of the social security schemes).

The information set out under the heading "What are my obligations?" is essentially the same as that set out in the IPIDs for contents insurance and third person motor liability insurance. However, industrial injury cover is subject to a special deadline for notifying Danish Labour Market Insurance and insurers C, E and $\mathrm{H}$ provide information about the deadline. All the insurance providers also mention that the customer (i.e. the employer) must inform the insurer of any changes in the business. Insurer $\mathrm{C}$ goes further and states that the customer must inform the insurance provider of any change to the risk of the business, albeit that it does not go on to explain precisely what is meant by this.

Under the headings "When and how do I pay?", "When does the cover start and end?" and "How do I cancel the contract?", the insurance providers set out essentially the same conditions as those set in respect of the IPIDs produced for contents insurance (and third party liability motor insurance), as to which see Sect. 3.3.2.2 above for analysis.

\subsection{Discussion}

\subsubsection{The Application of the Standardised Presentation Format in General}

Common to the examined IPIDs is that all of them comply with the requirement that the information presented be restricted to the formal requirements as to the allowed two A4 pages. Moreover, each such IPID has been designed in accordance with EIOPA's standardised presentation format, cf. Articles 1, 3 and 4 of the Implementing Regulation.

As mentioned above, insurers D's and E's icon for "How do I cancel the contract?" is not as prescribed in Article 7(1)(h) of the Implementing Regulation. Moreover, insurer F's IPID for the workers' compensation insurance does not 
include the heading "What is this type of insurance?" as prescribed in Article 6(1) (a) of the Implementing Regulation (see also Article 20(8)(a) of the IDD).

Each IPID states at the top of the document that it only gives a general overview of the insurance product, which statement is in compliance with Article 2 of the Implementing Regulation, and the customer is referred to the underlying policy terms for the complete pre-contractual and contractual information.

The design of the IPIDs is, therefore, broadly comparable and the small deviations from the standardised format which could occur, and which do in practice occur, is, in the authors' view, not a significant problem that must be addressed.

\subsubsection{The Heading "What Is This Type of Insurance?"}

In summary, the information set out by the insurance providers to describe the type of insurance offered is characterised by significant differences in the level of detail provided. Some insurance providers describe only the basic (i.e. minimum statutory) cover very briefly, whereas others use several lines to explain the cover or to mention possible add-ons.

The result is that it is not clear that the insurance products on offer are, in fact, more or less identical. In particular, one would expect that at least the description of the compulsory insurances, i.e. third person motor liability insurance and workers' compensation insurance, would be (on the whole) identical, which is not the case.

\subsubsection{The Headings "What Is Insured?", "What Is Not Insured?" and "Are There Any Restrictions on Cover?"}

The sections about the cover provided by the various insurance products, and the exclusions and restrictions to which such cover is subject, are not dealt with in the same manner by the various insurance providers. This is especially clear when one looks at the IPIDs for non-compulsory contents insurance, which often make clear that one insurance provider might set out cover that the other providers do not. It seems to be more or less (from the customer's perspective) a matter of chance whether cover is mentioned or not.

Sometimes specific cover is not mentioned in the IPID even though it is actually covered by the insurance. In the context of contents insurance, such is the case in respect of insurers $\mathrm{A}, \mathrm{C}$ and $\mathrm{D}$, each of which do not mention that luggage is covered, even though, upon examination of the relevant underlying policy terms, it is apparent that it is. Elsewhere in the IPIDs, specific cover is not mentioned but such omission is consistent with the fact that cover is not actually provided by the insurance. This is the case, for example, in respect of insurer $\mathrm{E}$, which does not mention, or indeed cover, identity theft. The same applies to exclusions. For example, insurer $\mathrm{C}$ is the only provider which mentions that windsurfers and kite surfers are not covered. An analysis of the other insurers' policy terms shows that windsurfers and kite surfers are covered by insurers $\mathrm{B}, \mathrm{D}$ and $\mathrm{E}$, but not by insurer $\mathrm{A}$. 
The scope for customer confusion is, in the authors' view, obvious. Customers cannot trust the IPIDs to provide an effective basis of general comparison or to provide much more than a very superficial indication of cover, exclusions and restrictions. As such, notwithstanding the fact that a customer might have access to a variety of IPIDs, such customer has to read other detailed documentation or the insurance provider's underlying policy terms to find out whether cover not explicitly mentioned in the IPID is or is not included in the product. In the authors' view, what is perhaps most worrying is not that customers have to undertake this arduous task, but that they might not even realise that they need to do so.

The problem is less severe in respect of the compulsory insurance products, which, in reality, also have more or less identical cover. However, there are examples of the same problem as has been observed with contents insurance. For example, in the context of third-party motor liability insurance, even though the cover offered by the various insurance providers in relation to injuries to the driver is essentially the same, the IPIDs do not give this impression. Instead, the providers often decide to set out information about their add-ons and to emphasise various exclusions.

The authors' analysis shows that insurance providers do not necessarily deal with the specific cover in the same way. The consequence is that where an insurance provider does not explicitly mention specific cover that another provider does, the customer cannot actually use the IPIDs as a basis of comparison, but instead has to read the providers' underlying policy terms in order to be able to make a comparison.

The analysis also shows that the insurance providers tend to emphasise elements that relate to their add-ons. Whereas some insurers clearly specify, by, for example, using sub-headings, if a particular element relates to the basic cover and if something relates to the add-ons (for example insurer $\mathrm{D}$ in respect of third person motor insurance), other insurers list elements without making it clear whether such elements relates to the basic cover, or the add-ons. The result is that the IPIDs are not an effective tool for making comparisons even in a pre-contractual phase.

The aforementioned tendency also applies to the information set out regarding restrictions. There seems to be some confusion amongst insurance providers about the information required to be provided in "What is not insured?" and in "Are there any restrictions on cover?". Some providers set out exclusions in "What is not insured?" whilst others set out the same exclusions in "Are there any restrictions on cover?" (see for example the contents insurance exclusions regarding lodgers). It could be argued that such a discrepancy does not actually affect the utility of the IPIDs as a basis of comparison, but, all other things being equal, it is not useful if the insurance providers and the customers must use a standardised document where it is possible to describe the same element under different headings, particularly where it would be relatively straightforward to solve the problem by specifying the information to be included in the IPID headings.

It appears from Articles 6(1)(e) and (f) of the Implementing Regulation that insurance providers must set out "information on a summary of the excluded risks" in the paragraph "What is not insured?", whereas the paragraph "Are there any restrictions on cover?" must include "information on the main exclusions". 
There is no other guidance on the information to be included in the IPIDs. It was pointed out in connection with EIOPA's consultations regarding the presentation format that the distinction could be a problem. ${ }^{27}$ At the time of the consultations, the sections were entitled "Main risks not covered" and "Main restrictions and exclusions".

In the authors' view, the concerns expressed are justified and it does not seem as if EIOPA changing the wording has fixed the problem. There is still an overlap between the sections and the insurance providers sometimes mention the same exclusion in two different sections.

\subsubsection{The Heading "Where Am I Covered?"}

The insurance products analysed by the authors all have essentially the same geographical area of cover. However, it is not always clear from the IPIDs that this is the case. Insurance providers adopt different approaches: some only mention the basis (in this case Denmark), but others also mention any restrictions that could be perceived as a geographical restriction. However, it might be more appropriate for such restrictions to be included under the headings "What is not insured?" or "Are there any restrictions on cover?" (for example, information about furniture and household effects in seasonal dwellings not being covered by contents insurance).

Further, the descriptions of the same geographical area of cover vary in such a way that it may not be completely clear to a customer what area the insurance actually covers. For example, customers who are not familiar the "green card scheme" would have to find out whether the geographical area "Denmark and the countries that are part of the "green card scheme"" is the same geographical area as "Europe and countries that are part of the "green card scheme"”. The risk is, of course, that customer's will not bother to conduct such independent research but will simply make decisions (which may be ultimately deleterious) based on assumptions.

The same applies in respect of the workers' compensation insurance, where the area of cover is governed by statute and is, consequently, the identical across policies, but where the insurance providers adopt differing approaches to describing the same geographical area.

\footnotetext{
${ }^{27}$ The Belgian Insurance Association (Assuralia) stated that:

[...] the information to be given in those sections could be (partially) dublicative as both sections are strongly interlinked, especially from a customer's point of view. In case EIOPA insists on maintaining both sections, more clarification has to be provided on the differences between the information to be presented.
} 


\subsubsection{The Headings "What Are My Obligations?", "When and How Do I Pay?", "When Does the Cover Start and End?" and "How Do I Cancel the Contract"}

The headings "What are my obligations?", "When and how do I pay?", "When does the cover start and end?" and "How do I cancel the contract?", which contain practical information for the customer, are worded differently by the various insurance providers. However, such differences do not, on their face, undermine a customer's ability to use the IPIDs to perform an effective comparison of the products. For example, the fact that one insurance provider explicitly states that the customer must pay on time, whereas the other providers do not, is unlikely to give the customer the impression that some insurance providers do not expect a customer to pay on time. Accordingly, it is the authors' view that, in respect of these headings (reflecting Articles 6(1)(g), (h), (i) and (j) of the Implementing Regulation with reference to Article 20(8)(c), (e)-(i) of the IDD), the IPIDs can form a useful basis for comparison.

\subsubsection{The Description of Add-Ons in the IPID}

As set out in the preceding section, insurance providers often set out in their IPIDs the add-ons available to the cover offered, rather than focusing on the cover provided as standard. In its draft technical standards EIOPA stated that any customer personalisation should be done via the policy terms and conditions, not in the IPID. ${ }^{28}$

This could be interpreted to mean that any add-ons which go beyond the basic cover should not even be mentioned in the IPID. Indeed, concerns were expressed by the trade organisations in their responses to EIOPA's consultations regarding the possibility of including add-ons in the IPIDs. ${ }^{29}$

\footnotetext{
${ }^{28}$ Draft Implementing Technical Standards concerning a standardised presentation format for the Insurance Product Information Document of the Insurance Distribution Directive of 7 February 2017, EIOPA-17/056, page 4, section 6.

${ }^{29}$ For example, FSCP stated that:

[...] The panel recommends EIOPA to require additional IPID's be made available to consumers when offered add on policies. This can be the case with legal insurance attached to home insurance for example. A single IPID will not capture all the terms and conditions of such separate policies and be misleading to consumers. As such, any separate policy should be subject to a separate IPID. (see Comments received by FSCP on EIOPA-CP-16-007: Consultation Paper on the proposal for the Implementing Technical Standards on a standardised presentation format of the Insurance Product Information Document (IPID) under the Insurance Distribution Directive (IDD), page 2).
}

See also Test Achats who expressed a similar point of view and stated that:

[...] A single IPID on two pages of an A4 page becomes a misleading document if it has to summarize the key information of more than one cover of a multi-risk policy. (see Comments received by Test Achats on EIOPA-CP-16-007: Consultation Paper on the proposal 
However, Recital 3 of the Implementing Regulation provides that:

In order to provide customers with product information which is easy to read, understand and compare, a common design, structure and format should be used when presenting the information referred to in Article 20(8) of Directive (EU) 2016/97 in the standardised insurance product information document referred to in Article 20(5) of that Directive, including by way of the use of icons or symbols. Equally, information about add-ons and optional covers, if any, should not be preceded by ticks, crosses or exclamation marks [...] (emphasis added)

As such, it appears as if the Implementing Regulation expressly contemplates a description of possible add-ons in the IPIDs, even though the possibility of add-ons is not actually mentioned in Article 20(8) of the Directive and even though the most natural understanding — when one must apply the standardised format to all insurance products alike - of a specific insurance product's main features does not include whether or not it is possible to buy extended cover. Accordingly, one can conclude that the concerns expressed by the trade organisations were not taken fully into account.

The conclusion of the authors' analysis is that the description of any add-ons seems to cause significant confusion in practice. Such confusion arises because different insurance providers decide to include the description of possible add-ons under different headings and because the descriptions in some instances take up the same or more space than the description of the basic cover provided by the product.

For example, some insurers describe the add-ons in the paragraph "What is insured?" and others describe it in "What is this type of insurance?" or "What is not insured?". Even in a best-case scenario, i.e. where identical information is provided by different insurers but under different headings, it is yet another instance where confusion might undermine the effectiveness of the IPID as a tool for customers to make informed comparisons between insurance products, which, in turn, undermines the objective the rules were initially designed to achieve.

Furthermore, one might question why insurance providers decide to set out information about add-ons in the paragraph "What is this type of insurance?". Following to a literal interpretation of the heading, it is not relevant for the description of the type of insurance that the scope of cover of the insurance can be extended by add-ons. The authors have not interviewed any of the insurance providers or asked them questions about their selection of method in connection with this chapter. However, one explanation might be that some insurance providers want to appear more flexible and when providing information about add-ons. Another explanation might be that insurance providers want to distinguish their insurance product from those offered by other providers. The latter explanation is likely correct when it comes to insurance products where an insurance provider's basic cover is governed by statute, for example third person motor liability insurance and workers'

for the Implementing Technical Standards on a standardised presentation format of the Insurance Product Information Document (IPID) under the Insurance Distribution Directive (IDD), page 2). 
compensation insurance. The authors fully acknowledge that the information about add-ons can be an important feature of the insurance product and can help give the customer an actual basis for choosing one insurance provider instead of another. However, when considering the purpose of the IDD and the IPID such considerations seems to come second to customer clarity regarding the basic features of an insurance product.

Another problem with setting out information on add-ons is that it is not always clear when the information about the cover, an exclusion from cover, or a restriction on cover is about the basic insurance offering and when it is a possible add-on. In this respect, there is, in the authors' view, clearly scope to improve the guidance given to insurance providers about not only the information to be included in the IPID, but also the best manner in which to present such information in order that customers actually get an IPID that provides a useful pre-contractual basis of comparison.

The authors wholeheartedly support the idea that insurance providers be afforded the opportunity to not only distinguish their insurance products from those products offered by competitors, but also to customise their insurance products so that the insurance offered matches the customer's demands and needs in the best way possible. However, the authors are also of the view that, based on the analysis carried out, that the IPID, in its current format and without any detailed guidance about how insurance providers should provide the required information, is not wellsuited to contain a description of possible add-ons and extensions. In the opinion of the authors the possibility of the insurance providers to detail possible add-ons without this influencing on the clarity of the description of the basic features of an insurance product should be addressed.

\subsubsection{The Use of Plain Language in the IPID}

When analysing the IPIDs, the authors discovered a tendency for insurance providers to use legal terms such as "gross negligence", "theft other than burglary", "intention", and "subrogation". The authors also found references to the "green card scheme" in the description of the geographical area of cover of the compulsory third person liability insurance. The tendency to use legalistic language and somewhat technical terminology is, to a degree, understandable. However, the authors would query it might be considered that the IPIDs fail to comply with the requirement to use plain language and not any jargon, as to which see Article 5 of the Implementing Regulation.

It is certainly debatable whether any legalistic language is, on its face, plain language and, if not, whether it should be avoided. On the other hand, it could be argued that if insurance providers are not allowed to use ordinary legal terms such as "gross negligence", then they will have to explain what the term means. That would mean that the limited space available to insurance providers would be used for long explanations about what the legal terms mean. This is plainly inexpedient, in conflict with the object of the IPID to contain information about the main features of the insurance product, and not at all useful to customers. 
Arguably, as long as there is consistency between the various legal terms used by insurance providers, the use of such terms would seemingly not be a problem when making a comparison between the IPIDs.

\subsection{Summary and de lege ferenda}

The authors' general conclusion following the analysis of the IPIDs is that insurance providers do, essentially, follow EIOPA's standardised presentation format. Visually, the IPIDs appear to be comparable and in accordance with the general objective of the rules.

However, the various IPIDs differ significantly when it comes to the information set out by insurance providers regarding the particular cover offered in the individual insurance products.

It is, in the authors' view, likely that the reason for such differences is that no rules or guidelines have been established for the information to be included in the IPID. The insurance providers themselves are thus able to decide on the information which they believe is relevant to the customer for each insurance product. As has been demonstrated by the analysis of the IPIDs, such decisions often differ, despite the fact that the insurance products and cover are, in most cases, all-but identical.

As discussed above, EIOPA's consultations emphasises that, in relation to technical standards, the objective of the IDD was to find a balance between providing the required flexibility to enable insurance providers to set out the relevant information, but at the same time ensuring that the IPIDs did not become a duplicate of the full insurance conditions. Several trade organisations stated during EIOPA's consultations that an IPID should only include the main features of a product, as a summary of several areas of cover in the same IPID would be an impossible task which would inevitably result in a misleading document (see for example the responses from Test Achats and FSCP). However, the concerns expressed by the trade organisations did not lead to any change in the format of the IPID and no guidelines for the information to be included in the IPID were issued.

The authors' analysis of the IPIDs demonstrates that the concerns expressed by the trade organisations were born out. In this regard, there are two main problems with the information provided in the IPIDs.

First, the cover, exclusions and restrictions that each insurance provider decides to emphasise in a particular IPID seems, from a customer perspective at least (one must assume the providers have their reasons) to be a matter of mere chance. The result is that customers cannot conclude from the fact that an insurance provider has not mentioned a specific type of cover, which is in fact mentioned by another issuer, that there is actually not a big difference, or even any difference at all, between the products. It means that, in most cases, the customer will have to make a comparison of the insurance products based on other detailed information or the underlying policy terms. That is, of course, assuming that the customer realises that they need to consult such detailed information. There is, in the authors view, the very real risk that 
the customer will simply make assumptions based on the IPID and may therefore be misled as to which product is best suited to their demands and needs.

Second, many insurance providers set out information relating to potential add-ons as well as the basic cover offered. The inclusion of information about potential add-ons means that the information in the IPID about the basic cover is necessarily more superficial (because, quite simply, there is not enough space). However, it also means that often it is not clear whether specific cover, a specific exclusion or a specific restriction relates to the basic cover or the add-ons.

The requirements as to the information to be provided in the IPIDs appears to be so flexible that, at least for the purposes of comparing near-identical products, they are almost inevitably unsuitable. There is no question that the IPIDs are suitable for comparing a product that has very broad cover with a product that has very restricted cover. However, if the products that the customer is looking for and wants to compare do not differ or only differ slightly, then the result of the aforementioned flexibility is that the IPIDs are not suitable for making an informed or useful comparison and do not fulfil the intended object of the IDD.

In reality, there is a risk that the current IPIDs give distorted information about what the insurance products actually cover and do not cover. This could confuse and mislead a customer when such customer is trying to use the IPIDs to make a comparison between products. It is also a poor outcome for the insurance providers, who have spent time and resources on an instrument which, at best, does not facilitate a useful comparison and, at worst, means that customers can be lost because, unlike one of its competitors, an insurance provider has decided not to mention specifically required (but optional) cover in its IPID. It also leaves the insurance providers in a grey area in which it is uncertain whether or not the provider meets the requirements laid down in Article 20 of the IDD. It should be noted in this regard that Article 33(3) of the IDD prescribes that, in the event of any breach of the rules on the conduct of business, including Article 20, Member States must ensure that, as a minimum, the competent authorities have the power to decide that the responsible natural or legal person must cease the conduct and refrain from repeating such conduct and to withdraw the registration of insurers subject to Article 3 (insurance intermediaries and others). Such drastic consequences illustrate the risks posed by insurance providers being left in a state of confusion regarding their regulatory obligations.

The question is: is it possible to transform the IPIDs into a more useful basis of comparison whilst, at the same time maintaining the current visual design and the manageable 2 A4 pages?

If IPIDs that can actually be used as an effective basis of comparison are to be drawn up, it is the authors' opinion that detailed guidelines for the information to be included in the IPIDs must be established and an industry-wide understanding of how particular terms are used must be in relevant insurance sectors.

In this connection, the authors note that EIOPA's draft implementation standard provided that the IPID must facilitate an easier understanding of an insurance 
product's main characteristics. ${ }^{30}$ The problem is, of course, that it is up to the insurance providers themselves to define what such main characteristics are and the analysis set out above shows that the different providers adopt distinctly different approaches in determining what such main characteristics are.

One solution might be to set out the basic cover of the insurance product in question in the IPIDs in a tick-box list. ${ }^{31}$ If, for example, the scope of cover was determined by national trade associations, this would at least mean that, all things being equal, all IPIDs for the same insurance product would include the same cover. As such, customers would be provided with a useful basis of comparison in respect of the most common areas of cover in a Member State, even though it would, arguably, be somewhat superficial.

The problem with such a solution is, arguably, that, in reality, a one-size-fits-all approach would make it very difficult for insurers to distinguish themselves from the others. It would be particularly difficult in respect of the compulsory insurance such as workers' compensation insurance where the cover is governed by statute (although one might also query whether it is of any value at all to have IPIDs for insurance products whose cover is dictated by law). Such difficulty in distinguishing insurance providers would, in turn, arguably make it more difficult for customers to actually make a decision as to which insurance provider to choose. Insurance providers and customers would be left with a situation in which an insurance provider who distinguishes themselves by having specific cover, would only be able to demonstrate this distinction if the specific cover was included in the list of boxes chosen by the national trade association.

Another proposal might be to draw up the IPIDs as proposed by the Dutch Association of Insurers (see Sect. 3.2). One consequence of such an approach would be that the format of the IPIDs would have to be designed specifically for each insurance product. For example, it means that the IPIDs for contents insurance and third person motor liability insurance would have two different formats. Those different formats would then be tailored appropriately to set out what cover is provided, what is excluded and whether something is, or is not, an add-on. For instance, a contents insurance IPID might contain a separate heading for luggage and insurance providers would then be able to specify whether or not luggage is covered.

\footnotetext{
${ }^{30}$ Draft Implementing Technical Standards concerning a standardised presentation format for the Insurance Product Information Document of the Insurance Distribution Directive of 7 February 2017, EIOPA-17/056, page 22.

${ }^{31}$ During the preparatory work for the IDD it was emphasised by the European Conservatives and Reformists (ECR), among others, that it was seen as a positive thing that the Directive was flexible instead of stipulating one-size-fits-all conditions. The ECR also stated that it applauded that the Directive gave the insurers room to make sure that customers got the best outcome instead of using tick-box-style exercises (see Ashley Fox on behalf of the ECR Group in the debate on 24 November 2015 in Strasbourg, CRE 24/11/2015-4 concerning A8-0315/2015; Supplementary report on the proposal for a directive of the European Parliament and of the Council on insurance mediation (recast), $\mathrm{COM}(2012) 0360)$. A proposal to regulate at EU level will hardly be applauded by the ECR.
} 
Notwithstanding these potential advantages, however, the uniform format of the IPID does have a number of advantages which would, of course, be lost.

None of the proposals mentioned above require that significantly more information would have to be provided than that which is set out in the current IPIDs. As such, a customer demanding more unusual cover, for example for windsurfing and kitesurfing, would consequently still have to read the insurance providers' underlying policy terms in order to get a proper basis for comparing products. The proposed solutions would also result in the risk that the insurance providers offering very complex insurance or package deals would not have sufficient flexibility to show what they are actually offering. However, that may not be a bad thing; after all, given that the IPID's are targeted at consumers, one must endeavour to achieve the objective of keeping the IPIDs simple and customer friendly.

A less intrusive proposal is that EIOPA provides some guidelines that determine the information that is most obvious to include under the various key headings, e.g. "What is insured?", "What is not insured?" and "Are there any restrictions on cover?". As for the IPIDs analysed by the authors, the consequence for the insurance providers would be that the flexibility to adopt differing approaches to the information they set out in the IPID would be maintained (albeit slightly curtailed), but the consequence for the customers would be that it will be easier to compare the IPIDs and make informed decisions. All other things being equal, it would, in the authors' opinion, be particularly advisable for national bodies to issue guidelines for uniform descriptions of insurance where the scope of cover of such insurance is prescribed by law.

It is, of course, difficult to determine where the balance as to what information should or should not be included in the IPIDs should lie. However, the confusion surrounding the specification of add-ons seems to be relatively easy to clear up. One solution might be to add in a heading which deals solely with add-ons to the IPID in its current format. The risk is that it would result in the same problems as the other area of cover if it is left to the insurance providers themselves to decide what add-ons to include under such a heading. However, it would solve the current problem whereby insurance providers inconsistently include add-ons in either "What is insured?", "What is this type of insurance?" or in "What is not insured?". Alternatively, EIOPA could provide guidance on where the description of add-ons belongs most naturally in the IPID and how to inform the customer that the information relates to possible add-ons rather than the basic scope of coverage.

\section{Conclusion}

The objective of this chapter has been to examine whether the rules on the IPIDs mandated by Article 20(1) of the IDD satisfy the objective of increasing customer protection in connection with the sale of insurance products.

An examination of selected IPIDs has demonstrated a discrepancy between the coverage that the insurers choose to emphasize in their IPID for a specific insurance 
product. Such discrepancies occur notwithstanding the fact that the products in question often have all-but identical coverage (regardless of which insurance provider is offering the product). It seems reasonable to assume that the discrepancy is due to the lack of guidelines and rules given for the completion of the IPIDs, which in turn means that the insurance providers are, to an extent, groping in the dark when they determine what information is relevant in order to allow a prospective customer to conduct a useful comparison. Consequently, the IPIDs are not, in reality, comparable and customers are thus not able to make an informed decision based on an examination of the same. Moreover, the insurance providers spend time and resources on an instrument which does not fulfil its intended purpose. In order for the IPIDs to meet their objective, it is the authors' considered opinion that it is necessary to establish how the insurers can most effectively complete them and provide guidelines in respect of the same.

In summary, the rules on IPIDs do not seem to have resulted in increased customer protection to a significant extent, or indeed to an extent which corresponds to the amount of extra work the insurance providers have to carry out in order to attempt to comply with the rules. In the authors' view, however, this, is more due to the lack of guidance regarding completion of the IPIDs than it is due to problems with the rules on IPIDs themselves. As such, as things stand, the insurance providers do not seem to have any basis for acting other than the way in which they do. In the authors' opinion, it would be sensible to consider providing guidance on the rules on IPIDs when the review of the Directive takes place in 2021.

\section{Danish Legislation}

Danish Consolidated Act no 1324 of 21 November 2018, the Road Traffic Act (in Danish: færdselsloven)

Danish Consolidated Act no 216 of 27 February 2017, Workers' Compensation Act (in Danish: arbejdsskadesikringsloven)

\section{EU Legislation}

Directive 2002/92/EC of the European Parliament and of the Council of 9 December 2002 on insurance mediation

Directive (EU) 2016/97 of the European Parliament and of the Council of 20 January 2016 on insurance distribution (recast)

Directive (EU) 2018/411 of the European Parliament and of the Council of 14 March 2018 amending Directive (EU) 2016/97 as regards the date of application of the Member States' transposition measures 


\section{EU Preparatory Work}

Ashley Fox on behalf of the ECR Group in the debate on 24 November 2015 in Strasbourg, CRE 24/11/2015-4 concerning A8-0315/2015; Supplementary report on the proposal for a directive of the European Parliament and of the Council on insurance mediation (recast), $\operatorname{COM}(2012) 0360)$

Comments received by Assuralia to EIOPA-CP-16-007: Consultation Paper on the proposal for the Implementing Technical Standards on a standardised presentation format of the Insurance Product Information Document (IPID) under the Insurance Distribution Directive (IDD)

Comments received by Danish Insurance Association to EIOPA-CP-16-007: Consultation Paper on the proposal for the Implementing Technical Standards on a standardised presentation format of the Insurance Product Information Document (IPID) under the Insurance Distribution Directive (IDD)

Comments received by the Dutch Association of Insurers to EIOPA-CP-16-007: Consultation Paper on the proposal for the Implementing Technical Standards on a standardised presentation format of the Insurance Product Information Document (IPID) under the Insurance Distribution Directive (IDD)

Comments received by Eurofinas to EIOPA-CP-16-007: Consultation Paper on the proposal for the Implementing Technical Standards on a standardised presentation format of the Insurance Product Information Document (IPID) under the Insurance Distribution Directive (IDD)

Comments received by FSCP to EIOPA-CP-16-007: Consultation Paper on the proposal for the Implementing Technical Standards on a standardised presentation format of the Insurance Product Information Document (IPID) under the Insurance Distribution Directive (IDD)

Comments received by Test Achats to EIOPA-CP-16-007: Consultation Paper on the proposal for the Implementing Technical Standards on a standardised presentation format of the Insurance Product Information Document (IPID) under the Insurance Distribution Directive (IDD)

Commission Implementing Regulation (EU) 2017/1469 of 11 August 2017 laying down a standardised presentation format for the insurance product information document

Commission Staff Working Document Executive Summary of the Impact Assessment accompanying the document Proposal for a Directive of the European Parliament and of the Council on Insurance Mediation, SWD/2012/0192 final

Draft Implementing Technical Standards concerning a standardised presentation format for the Insurance Product Information Document of the Insurance Distribution Directive of 7 February 2017, EIOPA-17/056

Opinion of the Internal Market and Consumer Protection (30.4.2013) on the proposal for a directive of the European Parliament and of the Council on insurance mediation (recast) (COM(2012)0360 - C7-0180/2012 - 2012/0175(COD)), A7-0085/2014 
Proposal for a Directive of the European Parliament and of the Council on Insurance Mediation (recast), COM/2012/0360 final - 2012/0175 (COD)

Supplementary Report of the Committee on Economic and Monetary Affairs on the proposal for a directive of the European Parliament and of the Council on insurance mediation (recast) $(\mathrm{COM}(2012) 0360$ - C7-0180/2012 - 2012/0175 (COD)), A8-0315/2015

Open Access This chapter is licensed under the terms of the Creative Commons Attribution 4.0 International License (http://creativecommons.org/licenses/by/4.0/), which permits use, sharing, adaptation, distribution and reproduction in any medium or format, as long as you give appropriate credit to the original author(s) and the source, provide a link to the Creative Commons licence and indicate if changes were made.

The images or other third party material in this chapter are included in the chapter's Creative Commons licence, unless indicated otherwise in a credit line to the material. If material is not included in the chapter's Creative Commons licence and your intended use is not permitted by statutory regulation or exceeds the permitted use, you will need to obtain permission directly from the copyright holder. 